\title{
Elevated slabs made of hybrid reinforced concrete: Proposal of a new design approach in flexure
}

\author{
Luca Facconi (i) | Giovanni Plizzari | Fausto Minelli (1)
}

DICATAM - Department of Civil, Environmental, Architectural Engineering and Mathematics,

University of Brescia, Brescia, Italy

\section{Correspondence}

Fausto Minelli, DICATAM - Department of Civil, Environmental, Architectural Engineering and Mathematics, University of Brescia, Brescia, Italy. Email: fausto.minelli@unibs.it
When designing fiber-reinforced concrete (FRC) structures, one of the basic design issues is represented by the choice of a proper combination of fibers and conventional reinforcement that allows to obtain the best structural performance with the minimum amount of materials. The combination of rebars and fibers in the concrete matrix is generally known as Hybrid Reinforced Concrete (HRC). HRC represents a feasible solution in many structures; among these, slabs are gaining an increasing interest among practitioners. In fact, slabs are the most widespread structural elements in common practice as they are typically used to construct slabs on ground (industrial floors or foundations), slabs on piles (foundations) or elevated slabs. This paper focuses on the flexural design of FRC elevated slabs by using the most recent design provisions reported in the fib Model Code 2010. A simplified design procedure based on a consolidated design practice is proposed. Emphasis is given to the use of HRC to minimize the total reinforcement (fibers + rebars) in order to get practical and economic advantages during construction (ie, construction time and costs reduction). In more detail, a procedure for proportioning the hybrid reinforcement and then verifying the structural safety will be presented and discussed. Numerical nonlinear finite element analyses will be carried out to assess the effectiveness of the proposed design method.

\section{KEYWORDS}

design slabs, elevated slabs, fiber-reinforced concrete, hybrid-reinforced concrete, Model Code 2010, nonlinear finite element analysis

\section{1 | INTRODUCTION}

The use of steel fibers is a well-acknowledged methodology to improve the tensile performance and toughness of concrete. After several years of discussion within the research community, fiber-reinforced concrete (FRC) is nowadays recognized as a structural material considered by both international $^{1}$ and national ${ }^{2,3}$ structural codes. In addition to the better structural performances resulting from the enhanced mechanical properties, FRC allows a better shrinkage and crack control leading to an increased structure durability.

Discussion on this paper must be submitted within two months of the print publication. The discussion will then be published in print, along with the authors' closure, if any, approximately nine months after the print publication.
Slabs are typical applications of cast-in-place FRC, as they are used to build industrial pavements, ${ }^{4-6}$ floors for multistory buildings ${ }^{7}$ or foundations. Stress redistribution resulting from the high internal redundancy of these structures may allow to exploit the postcracking strength and toughness of FRC, leading to a possible reduction of conventional reinforcement. The partial or total substitution of conventional rebars allows reducing the construction time and costs that generally characterize the traditional reinforced concrete (RC) structures.

Tests carried out worldwide on full-scale slabs ${ }^{8-10}$ concerned specimens in which fiber reinforcement was used as primary flexural reinforcement able to completely substitute conventional rebars. When provided, the latter was usually 
placed at the bottom of the slab, only along columns or piles alignments, in order to avoid progressive collapse of the structure. ${ }^{11,12}$ The aforementioned tests highlight that the design loads typically applied on floors can be withstood with a steel fiber content higher than $70 \mathrm{~kg} / \mathrm{m}^{3}$. Accordingly, ACI $544.6 \mathrm{R}-15^{13}$ suggests to construct FRC elevated slabs by using steel fibers as the only primary reinforcement in combination with a minimum amount of rebars used as "antiprogressive collapse reinforcement." However, as shown by several research studies, fibers represent a highly performing reinforcement for resisting diffused stresses, whereas localized stresses are better resisted by rebars. ${ }^{14}$ This means that one can use fiber reinforcement only, ${ }^{15}$ but the amount of fibers should be significantly increased in the whole structure in order to resist high stresses acting only in small areas. This usually results in a higher amount of total reinforcement compared to alternative solutions based on a combination of fibers and rebars, herein defined as Hybrid Reinforced Concrete (HRC). ${ }^{16-21}$ Furthermore, it has to be remarked that the use of high fiber contents may cause a loss of workability and compactness of FRC leading to a reduction of the material tensile properties.

The design of FRC structures is generally quite difficult as the nonlinear tensile properties of the composite material have to be properly included in the calculations. Referring to FRC slabs, the design procedures suggested by the codes are usually based on the yield lines theory. ${ }^{12}$ The latter is certainly a powerful analytical tool but it cannot be easily implemented for proportioning and verifying slabs made with HRC. The use of advanced analyses procedures, like those based on nonlinear finite element models, are generally more suitable to get a proper prediction of the structural behavior but are not diffused among structural designers since nonlinear finite element codes are hardly available.

Based on the design requirements reported by fib Model Code $2010,{ }^{1}$ a simplified procedure for designing HRC elevated slabs is proposed herein. In addition to the bottom reinforcement generally used in FRC elevated slabs (ie, rebars along column alignments), top reinforcement is also placed over the columns to obtain the best performance in terms of global capacity of the structure. The resulting combination of fibers and rebars aims at minimizing total reinforcement (fibers + rebars) leading to an overall reduction of construction time and costs. The proposed design method is based on an initial linear elastic finite element analysis (LEFEA) to determine the bending moments used for proportioning the conventional reinforcement. The verification of the structural safety factors is performed by nonlinear finite element analyses (NLFEAs) including the postcracking tensile behavior of FRC.

It is worth noting that the proposed procedure focuses on the design of flexural reinforcement. On the contrary, when punching mechanisms govern the ultimate behavior of the structure, punching shear reinforcement must be designed according to MC2010. The investigation of the shear punching response of slabs designed according to the proposed method will be deeply investigated in a future work.

\section{2 | DESCRIPTION OF THE STRUCTURE AND OF THE PROPOSED DESIGN PROCEDURE}

The reference case study adopted herein is an elevated slab having the same geometry of that tested by Destrée and $\mathrm{Mandl}^{22}$ (Figure 1). The slab has three spans in both directions and is supported by 16 columns placed at a distance (axis-to-axis) of $6 \mathrm{~m}$.

The proposed design procedure consists of two main stages defined as "preliminary design stage" and "verification stage." The former concerns the preliminary analysis and design of the structure, which provides the slab thickness $(t)$ and a proper amount of fibers and of conventional reinforcement. The latter stage includes the verification of the structure both at ultimate limit state (ULS) and at serviceability limit state (SLS), by performing NLFEAs.

\subsection{Preliminary design stage (proportioning)}

The preliminary stage consists of the following main steps:

1. Choice of the slab thickness $(t)$ in order to limit the slab slenderness $(t / L=$ thickness/span length) in the range $1 / 35 \leq t / L \leq 1 / 25$.

2. Choice of mechanical properties of materials (FRC and reinforcing steel).

3. Determination of the design loads $\left(E_{d}\right)$. As required by the EN $1990,{ }^{23}$ all possible combinations of design loads must be considered to obtain the most critical values of the internal actions. The design load results from the following combination:

$$
E_{d}=\sum_{j \geq 1} \gamma_{G, j} \cdot G_{k, j}+\gamma_{P} \cdot P+\gamma_{Q, 1} \cdot Q_{k, 1}+\sum_{i>1} \gamma_{Q, i} \cdot \psi_{0, i} \cdot Q_{k, i}
$$

where $G, P$, and $Q$ represent permanent, prestressing, and variable actions, respectively; the coefficients $\gamma_{\mathrm{G}}, \gamma_{\mathrm{P}}$, and $\gamma_{\mathrm{Q}}$ are the partial factors for actions; $\psi$ is the factor for the combination of variable actions.

4. Determination of the internal actions through LEFEA.

5. Design of conventional reinforcement combined with fibers.

Based on the results of the LEFEA, the maximum design bending moments $\left(m_{\mathrm{Ed}, \mathrm{x}}, m_{\mathrm{Ed}, \mathrm{y}}\right)$ acting in the two orthogonal directions ( $x$ and $y$ ) can be evaluated as follows:

$$
\mathrm{m}_{\mathrm{Ed}, \mathrm{x}}=\mathrm{m}_{\mathrm{d}, \mathrm{x}} \pm\left|\mathrm{m}_{\mathrm{d}, \mathrm{xy}}\right| ; \mathrm{m}_{\mathrm{Ed}, \mathrm{y}}=\mathrm{m}_{\mathrm{d}, \mathrm{y}} \pm\left|\mathrm{m}_{\mathrm{d}, \mathrm{xy}}\right|,
$$

where $m_{\mathrm{d}, \mathrm{x}}$ and $m_{\mathrm{d}, \mathrm{y}}$ are the internal design bending moments in $x$ - and $y$-direction, respectively, whereas $m_{\mathrm{d}, \mathrm{xy}}$ is the internal design torsional moment. 
Elevated slab: plan view Dimensions in $\mathrm{mm}$
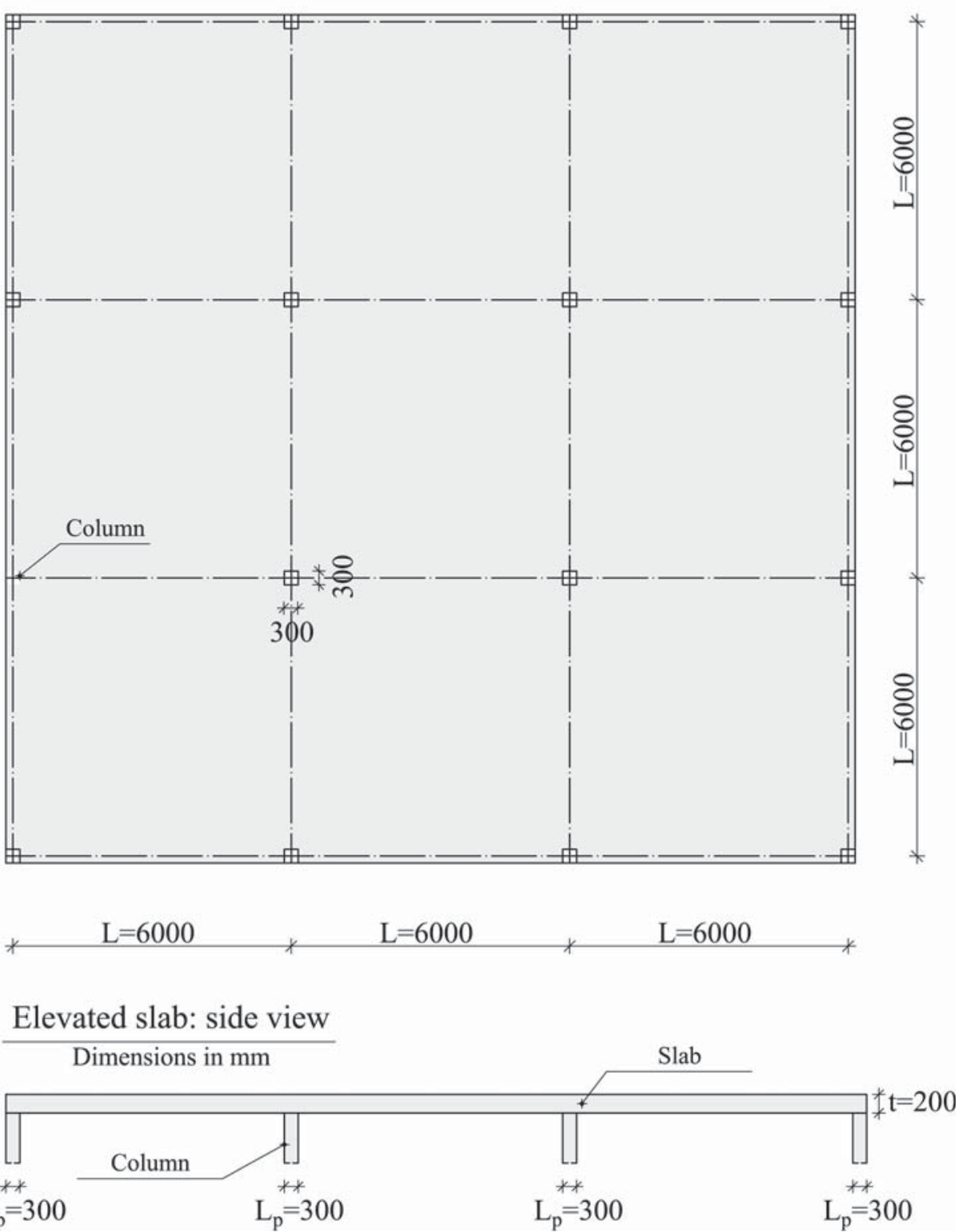

\section{Elevated slab: side view}

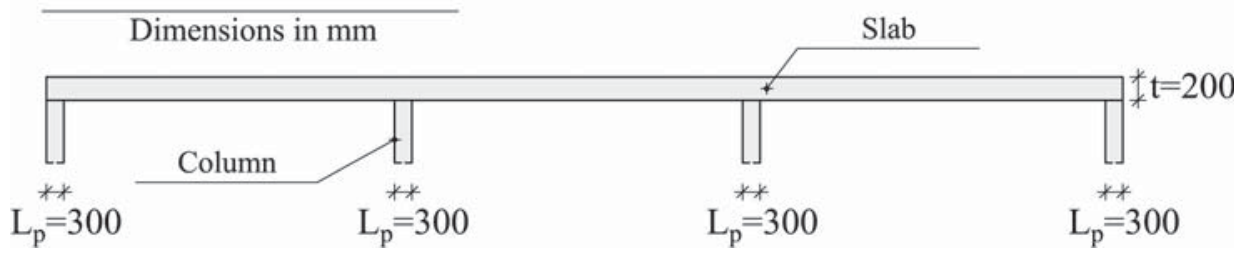

FIGURE 1 Geometry of the fiber-reinforced concrete elevated slab reported by Destrée and Mandl ${ }^{22}$ (Bissen slab)

The contribution to the internal resistance provided by fibers only may be evaluated by using the simplified crosssectional model depicted in Figure 2a, which assumes to represent the ultimate residual tensile strength $\left(f_{\mathrm{Ftu}}\right)$ with a constant stress distribution below the neutral axis depth $(x)$. The latter is assumed to be placed at a distance of 0.1 times the thickness $(t)$ of the slab from the compressed side. Therefore, the design resisting moment due to fibers only can be estimated by the following equation:

$$
\mathrm{m}_{\mathrm{Rd}, \mathrm{FRC}}=\frac{1}{2} \mathrm{f}_{\mathrm{Ftu}, \mathrm{d}} \cdot \mathrm{t} \cdot(\mathrm{t}-\mathrm{x})=0.45 \cdot \mathrm{f}_{\mathrm{Ftu}, \mathrm{d}} \cdot \mathrm{t}^{2},
$$

where $f_{\mathrm{Ftu}, \mathrm{d}}=f_{\mathrm{R} 3 \mathrm{k}} /\left(3 \times \gamma_{c}\right) ; f_{\mathrm{R} 3 \mathrm{k}}$ is the residual flexural strength at a crack mouth opening displacement (CMOD) of
$2.5 \mathrm{~mm}$ according to EN14651 ${ }^{24} ; \gamma_{c}=1.5$ is the partial safety factor for FRC according MC2010. The assumed value of the neutral axis depth, that is, $x=0.1 \cdot t$, is the representative of flat slabs containing low amounts of conventional reinforcement as the HRC slabs investigated in this work.

Additional reinforcement is required in the areas of the slab where the design internal bending moment $\left(m_{\mathrm{Ed}}\right)$ is higher than the resisting moment provided by fibers only $\left(m_{\mathrm{Rd}, \mathrm{FRC}}\right)$. It is clear that the higher is the resisting moment provided by fibers, the smaller is the amount of rebars required to withstand the design internal bending moment. This fact highlights the possibility of finding an optimized reinforcement resulting from the combination of rebars and fibers (HRC). 
(a)

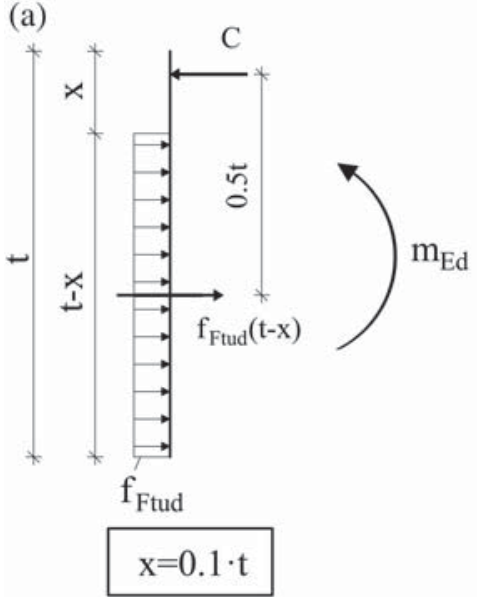

(b)

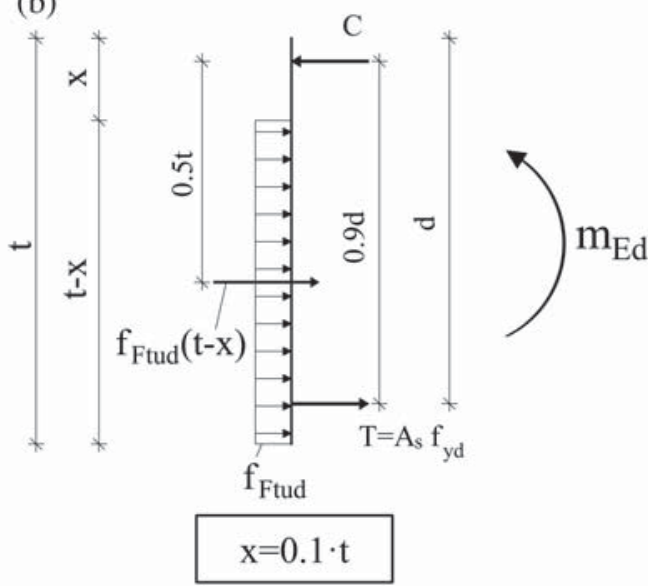

FIGURE 2 Proposed simplified model for a cross section reinforced only with fibers (a) or fibers in combination with conventional reinforcement (b)

In the following, the design procedure for the bending moments acting in $x$-direction will be presented (the same approach can be applied indifferently to the moments acting in $y$-direction) (see Figure 3). Even though the structural behavior of FRC slabs is markedly nonlinear after cracking, as a first approximation, the moment distribution provided by the LEFEA may be used to design the additional reinforcement.

Figure 3 shows the typical regions of the slab in which additional top and bottom rebars are required as the bending moment $m_{\mathrm{Ed}, \mathrm{x}}$ is higher than $m_{\mathrm{Rd}, \mathrm{FRC}}$. Those regions are derived from the envelope of bending moments obtained from the LEFEA. Note that, by considering the symmetry of the slab geometry, a quarter of the whole structure is here represented. In Figure 3, the white areas represent the parts of the slabs covered by fibers only whereas the dashed areas are the remaining portions of the slab in which additional rebars are needed.

Figure 4 shows the typical envelope curves of bending moments acting in the $x$-direction along four different sections of the elevated slab (ie, Figure 3, slab sections a-d). The intersection between the resisting moment provided by fibers (ie, $m_{\mathrm{Rd}, \mathrm{FRC}}$ ) and the envelope curves provides the length $\left(L_{\text {int }}\right.$-see Figure 3$)$ along which bending moments have to be integrated for determining the total area of conventional reinforcement. The latter turns out from the equilibrium of the cross section depicted in Figure $2 b$. Thus

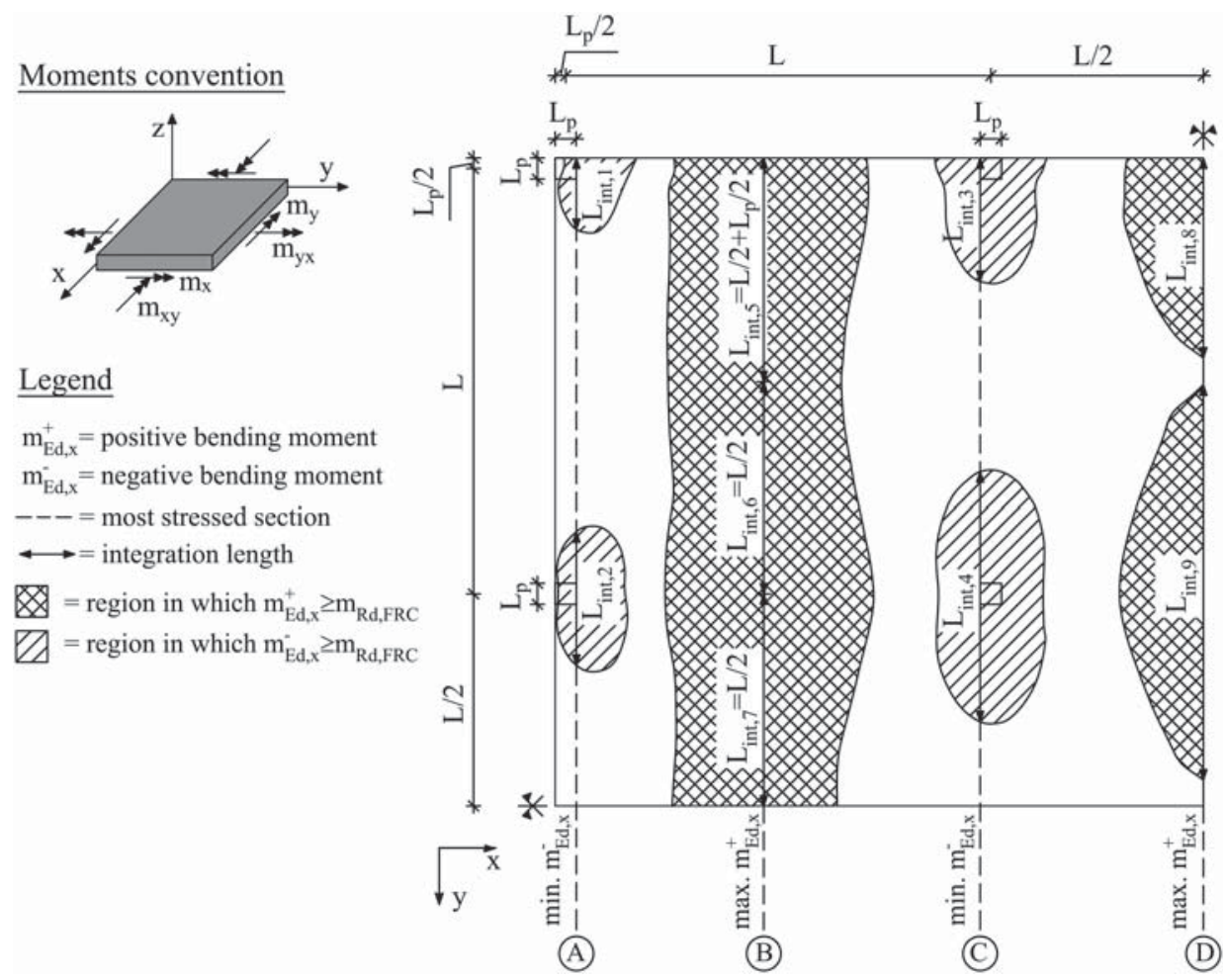

FIGURE 3 Typical regions of the slab in which additional top and bottom conventional reinforcement in $x$-direction is required 


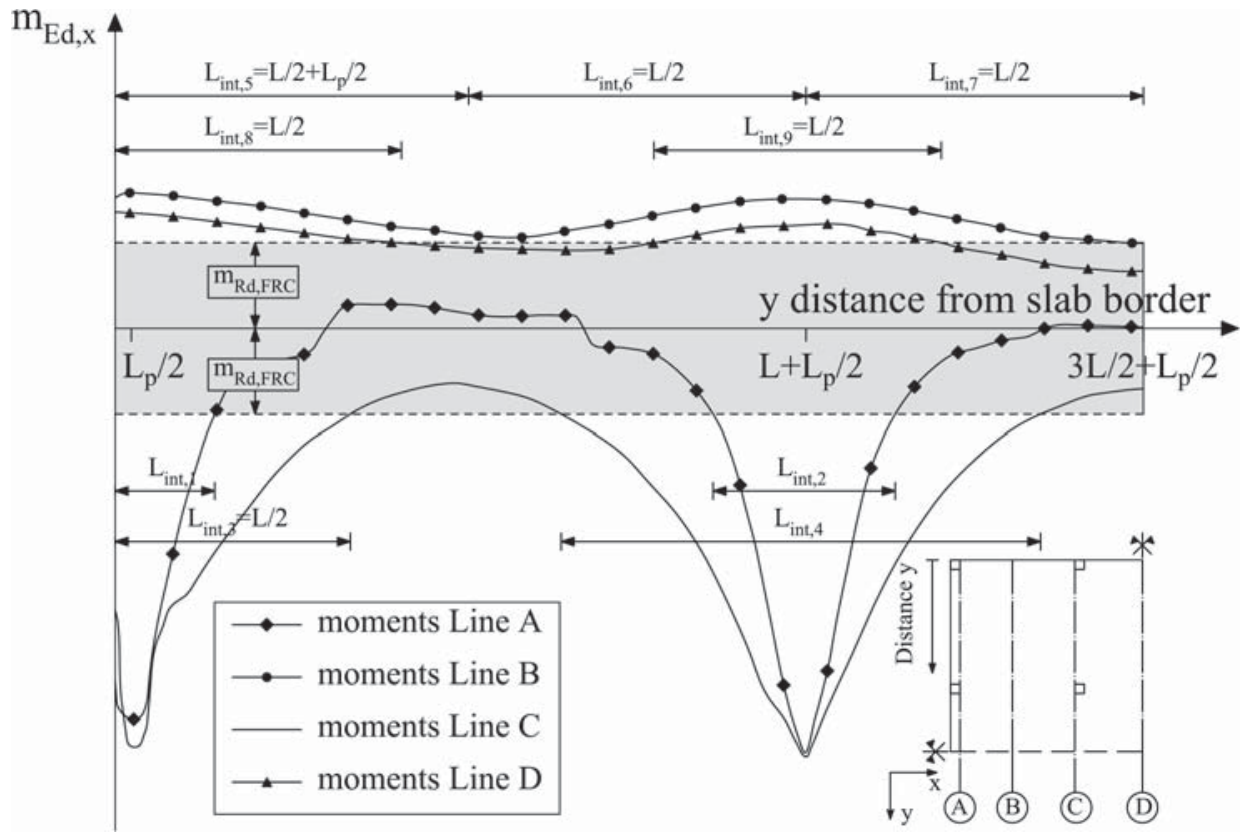

FIGURE 4 Typical distribution of the maximum and minimum design bending moments $m_{\mathrm{Ed}, \mathrm{x}}$ acting along the most critical section lines (lines A, B, C, and D)

$$
\begin{aligned}
& \mathrm{A}_{\mathrm{s}, \mathrm{x}}=\frac{\int_{0}^{\mathrm{L}_{\text {int }}}\left(\mathrm{m}_{\mathrm{Ed}, \mathrm{x}}-\mathrm{m}_{\mathrm{Rd}, \mathrm{FRC}}\right) \mathrm{dx}}{0.9 \cdot \mathrm{f}_{\mathrm{yd}} \cdot \mathrm{d}} ; \\
& \mathrm{A}_{\mathrm{s}, \mathrm{y}}=\frac{\int_{0}^{\mathrm{L}_{\text {int }}}\left(\mathrm{m}_{\mathrm{Ed}, \mathrm{y}}-\mathrm{m}_{\mathrm{Rd}, \mathrm{FRC}}\right) \mathrm{dy}}{0.9 \cdot \mathrm{f}_{\mathrm{yd}} \cdot \mathrm{d}},
\end{aligned}
$$

where $A_{\mathrm{s}, \mathrm{x}}$ and $A_{\mathrm{s}, \mathrm{y}}$ are the total required reinforcement areas in $x$ - and $y$-direction, respectively; $d$ is the effective depth of the slab; $f_{\mathrm{yd}}=f_{\mathrm{yk}} / \gamma_{\mathrm{s}}, f_{\mathrm{yk}}$, and $\gamma_{s}=1.15$ are the design yield strength, the characteristic yield strength, and the material safety factor of conventional reinforcing steel, respectively (see MC2010 ${ }^{1}$ ).

Once the minimum additional reinforcement has been defined, rebars have to be properly placed in some regions of the slab. A possible reinforcement layout is suggested by the schematic of Figure 5. As mentioned above, considering the symmetry of the slab geometry, only a quarter of the whole reinforcement layout has been represented. As one may observe, top reinforcement consists of rebars placed orthogonally over the columns. These bars are bent as shown in Figure $5 \mathrm{~b}$ in order to be easily placed during construction and to contribute to the punching shear resistance as well. In addition to top reinforcement, bottom continuum rebars (Figure 5c) are located along the column alignments. The length of each bar is defined to cover the region in which $\left|m_{\text {Ed,x }}^{-}\right| \geq m_{\mathrm{Rd}, \mathrm{FRC}}$.

Both international codes and literature have not provided clear rules dealing with flexural reinforcement layout in HRC slabs. It is well-known from elastic analysis that maximum principal bending moments are reached along the columns alignments. When designing the slab reinforcement to ensure the development of the beam flexural strength at column-beam joints, Paulay and Priestley ${ }^{25}$ suggest to put most of the top and bottom main reinforcement within a width not higher than two times the column width $\left(L_{p}\right)$. Here, in order to ensure a safe design, top and bottom rebars are spread over a width equal to $L_{p}+d \leq 2 L_{p}$, except for rebars placed along the border of the slab, which are laid over the width $L_{p}+0.5 \mathrm{~d} \leq 1.5 L_{p}$ (Figure 5). Moreover, bottom rebars provide continuity between columns, thus preventing the progressive collapse of the structure. Such a kind of reinforcement, generally referred to as integrity reinforcement, typically consists of straight bars running above the supported areas in the compression side of the slab. ${ }^{26}$ According to $\mathrm{MC} 2010,{ }^{1}$ when slabs without shear reinforcement or sufficient deformation capacity are considered, integrity reinforcement has to be adopted. The postpunching resistance provided by the integrity reinforcement $\left(V_{\mathrm{Rd} \text {,int }}\right)$ results from the following equation (MC2010 ${ }^{1}$ - clause 7.3.5.6):

$$
\begin{aligned}
& \mathrm{V}_{\mathrm{Rd}, \text { int }}=\sum \mathrm{A}_{\mathrm{s}, \text { int }}^{\mathrm{b}} \cdot \mathrm{f}_{\mathrm{yd}} \cdot\left(\frac{\mathrm{f}_{\mathrm{t}}}{\mathrm{f}_{\mathrm{y}}}\right)_{\mathrm{k}} \cdot \sin \left(\alpha_{\mathrm{ult}}\right) \leq \frac{0.5 \cdot \sqrt{\mathrm{f}_{\mathrm{ck}}}}{\gamma_{\mathrm{c}}} \cdot \mathrm{d}_{\text {res }} \\
& \cdot \mathrm{b}_{\text {int }}
\end{aligned}
$$

where $\sum \mathrm{A}_{\mathrm{s}}^{\mathrm{b}}$, int is the sum of the cross sections of all the integrity bottom rebars suitably developed and intersected by the failure surface; ratio $\left(f_{t} / f_{y}\right)_{\mathrm{k}}$ depends on the ductility class of reinforcement; $\alpha_{\mathrm{ult}}$ is the average angle of the bars with respect to the plane of the slab (eg, $\alpha_{\mathrm{ult}}=20^{\circ}$ or $25^{\circ}$, respectively, for ductility class $\mathrm{B}$ and $\mathrm{C}$ reinforcement); $f_{\mathrm{ck}}$ is the characteristic value ( $5 \%$ fractile) of the cylindrical compressive strength of concrete; $d_{\text {res }}$ is the distance between the centroid of top flexural and of integrity reinforcement; $b_{\text {int }}=\sum\left(s_{\text {int }}+0.5 \pi \mathrm{d}_{\text {res }}\right)$ is the control perimeter activated by the integrity reinforcement; and $s_{\text {int }}$ is the width of the group of integrity bars in one direction. Note that $A_{s}^{b}$, int 
(a) Typical slab section

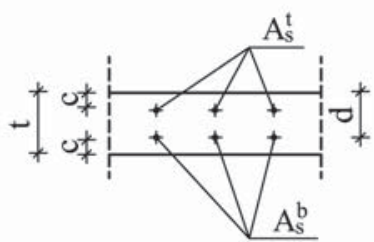

$\mathrm{c}=$ concrete cover

$\mathrm{t}=$ total slab thickness

$\mathrm{d}=\mathrm{t}-\mathrm{c}=$ effective depth

$\mathrm{A}_{\mathrm{s}}^{\mathrm{b}}=$ bottom rebars

$\mathrm{A}_{\mathrm{s}}^{\mathrm{t}}=$ top rebars

$\mathrm{L}_{\mathrm{p}}+\mathrm{d} \leq 2 \mathrm{~L}_{\mathrm{p}}$ (internal reinforement)

$\mathrm{L}_{\mathrm{p}}+0.5 \mathrm{~d} \leq 1.5 \mathrm{~L}_{\mathrm{p}}$ (border reinforement)

(c)

$\underline{\text { Bottom surface }}$

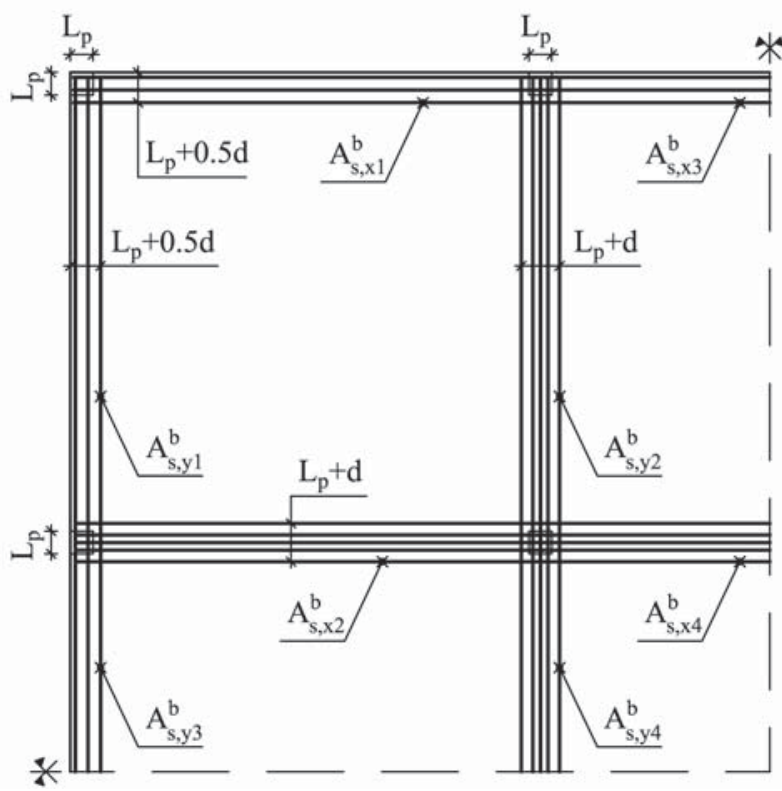

(b) Top surface



(d) Typical top reinforcement detailing

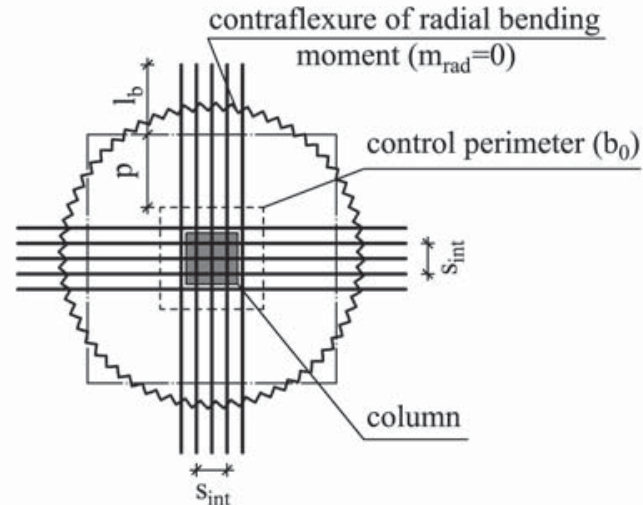

$\mathrm{p}=\min (2.5 \mathrm{~d} ;$ position of contraflexure line $)$

$\mathrm{b}_{0}=$ control perimeter (MC2010-clause 7.3.5.2)

$\mathrm{l}_{\mathrm{b}}=$ bar development length

FIGURE 5 Additional reinforcement detailing: (a) typical slab section; (b) top reinforcement layout; (c) bottom reinforcement layout; and (d) rules for determining top reinforcement length

represents the part of bottom reinforcement $\mathrm{A}_{\mathrm{s}}^{\mathrm{b}}$ placed within a width not larger than the column width in the relevant direction.

The rebar lengths $L_{\mathrm{s} 1}$ and $L_{\mathrm{s} 2}$ shown in Figure 5b represent the minimum net lengths resulting from bending design, excluding the anchorage length $\left(l_{b}\right)$ that should be added. In actual cases, to avoid crack localization for punching shear, the anchorage length of top rebars must start at the distance $(p)$ from control perimeter $\left(b_{0}\right)$ determined according to the scheme reported in Figure 5d. Further rules about detailing of rebars placed in the supported regions can be found in MC2010 ${ }^{1}$-clause 7.13.5.3.
No other conventional rebars should be used with the exception of those usually required to control crack formation in correspondence of concrete shafts, staircases, reentrant corners, and manholes.

\section{2 | Verification stage}

Based on NLFEAs, the following procedure is suggested to verify the effectiveness of the hybrid reinforcement provided by the preliminary (proportioning) design stage:

1. Determine the global resistance $\left(R_{d}\right)$ of the slab by NLFEA implementing the tensile constitutive laws of 
FRC suggested by the MC2010 (clause 5.6.4). The design condition for the global safety format proposed by MC2010 (clause 7.11.3) has the following form:

$$
\mathrm{E}_{\mathrm{d}} \leq \mathrm{R}_{\mathrm{d}}=\frac{\mathrm{R}_{\mathrm{m}}}{\gamma_{\mathrm{R}}^{*} \cdot \gamma_{\mathrm{Rd}}}
$$

where $R_{d}$ and $R_{m}$ are, respectively, the design and mean global resistance of the structure; $\gamma^{*}{ }_{\mathrm{R}}$ is the global resistance safety factor; and $\gamma_{\mathrm{Rd}}$ is the model uncertainty factor. Different approaches are suggested by MC2010 to determine the design resistance $R_{d}$ : (1) the probabilistic method (clause 7.11.3.2); (2) the global resistance factor method (clause 7.11.3.3.1); and (3) the method of estimation of a coefficient of variation of resistance (ECOV) (clause 7.11.3.3.2). If the global safety condition required by Equation (6) is not fulfilled, then a tougher FRC or additional reinforcement must be provided until an acceptable safety level is achieved.

It can be generally assumed that the resistance of the structure $(R)$ is approximately log-normal distributed and, thus, the global resistance safety factor $\gamma_{\mathrm{R}}^{*}$ may be represented by the exponential equation (Equation (9)) discussed in Section 3.2. The latter represents $\gamma_{\mathrm{R}}^{*}$ as a function of the coefficient of variation of resistance $\left(V_{R}\right)$ which, in turn, depends on the coefficients of variation associated with modeling $\left(V_{\theta}\right)$, geometrical $\left(V_{g}\right)$, and material $\left(V_{f}\right)$ uncertainties by the following equation:

$$
\mathrm{V}_{\mathrm{R}}=\sqrt{\mathrm{V}_{\theta}^{2}+\mathrm{V}_{\mathrm{g}}^{2}+\mathrm{V}_{\mathrm{f}}^{2}}
$$

As observed by Schlune et al, ${ }^{27}$ model uncertainty is usually the most important factor affecting the structure safety assessment, as it depends on the adopted modeling approach as well as the failure mode (eg, bending, shear, punching shear, and so on). A full discussion about the safety formats for nonlinear analyses is reported in Allaix et $\mathrm{al}^{28}$ and Belletti et al. ${ }^{29}$ The approach adopted in the following for safety assessment is the method ECOV.

2. Check the safety and serviceability minimum requirements for FRC structures according MC2010 (see clause 7.7).

3. Check the punching resistance of the slab. In order to obtain an accurate prediction of the punching resistance of FRC flat slabs, the use of the Level of Approximation IV reported by $\mathrm{MC}^{2} 010^{1}$ is recommended (clause 7.7.3.5.3) for FRC structures. A critical discussion on the verification of FRC slabs subjected to punching can be found in Maya et $\mathrm{al}^{30}$ and Belletti et al. ${ }^{31}$

\section{3 | VALIDATION OF THE NUMERICAL FINITE ELEMENT MODEL}

In order to validate the numerical model used to perform the simulations discussed in the following sections, the experimental tests on full-scale elevated slabs reported by Destrée and $\mathrm{Mandl}^{20}$ and Parmentier et $\mathrm{al}^{9}$ were simulated with the finite element (FE) program Diana 10.1. ${ }^{32}$ Experiments concerned two slabs, namely, "Bissen slab" and "Limelette slab." The two structures consisted of nine bays with three continuous spans per each direction having an equal span of $6 \mathrm{~m}$. The slabs had a constant thickness of $200 \mathrm{~mm}$ and were supported by a total of 16 equally spaced columns. In more detail, 300-mm-side square columns supported the Bissen slab whereas the Limelette slab was placed on 300-mm-diameter circular columns. Thus, the FE models used to simulate the two structures were similar, with the exception of the different discretization adopted for the mesh regions supported by columns. In order to investigate the structure behavior under ultimate conditions, a point load applied in the middle of the slab was increased monotonically till failure. Because of the double symmetry, only a quarter of the whole slab was modeled by a total of 4,850 eight-node isoparametric flat-shell elements. Rigid constraints were adopted to reproduce the support of the columns in vertical direction (z-direction). A schematic of the FE models used to simulate the two slabs is depicted in Figure 6.

Fracture behavior of concrete was simulated by the "Total Strain Rotating Crack Model". 33

The compressive behavior of concrete was represented by the parabolic stress-strain relationship suggested by the MC2010 ${ }^{1}$ (clause 5.1.8):

$$
\sigma_{\mathrm{c}}=-\mathrm{f}_{\mathrm{cm}} \cdot\left(\frac{\mathrm{k} \cdot \eta-\eta^{2}}{1+(\mathrm{k}-2) \cdot \eta}\right) .
$$

where $f_{\mathrm{cm}}$ is the mean cylindrical compressive strength; $\eta=\varepsilon_{c} / \varepsilon_{\mathrm{c} 1}, \varepsilon_{\mathrm{c} 1}=0.7 \cdot f_{\mathrm{cm}}{ }^{0.31}$ is the strain at peak strength; $k=1.05 E_{\mathrm{cm}}\left|\varepsilon_{\mathrm{c} 1}\right| / f_{\mathrm{cm}}$ is the plasticity number; and $E_{\mathrm{cm}}=22$ $\cdot 10^{3} \cdot\left(f_{\mathrm{cm}} / 10\right)^{0.3}$ is the mean secant modulus of elasticity evaluated at $0.4 \cdot f_{\mathrm{cm}}$ (Table 1 ).

The tensile behavior of concrete was considered linear elastic up to the mean tensile strength $\left(f_{\mathrm{ctm}}\right)$ and to the corresponding strain $\left(\varepsilon_{\mathrm{ct}}=f_{\mathrm{ctm}} / E_{\mathrm{cm}}\right)$. On the contrary, the postcracking behavior of FRC was represented by trilinear stress $(f)$-crack width (w) laws. As typical for smeared crack models, cracks were distributed over a crack bandwidth $\left(L_{\mathrm{ch}}\right)^{31,34}$ whose value was assumed equal to the square root of the area of each FE. As suggested by Rots, ${ }^{33}$ the value of $L_{\mathrm{ch}}$ was used to turn the tensile f-w law of FRC into the corresponding stress-strain relationship implemented in the FE model.

The tensile properties of the FRCs (see Table 1) used in the simulation of the Limelette and Bissen slabs were derived from test results reported by di Prisco et $\mathrm{al}^{35}$ and Soranakom et $\mathrm{al}^{36}{ }^{36}$ respectively. FRC used in the Limelette slab contained $60 \mathrm{~kg} / \mathrm{m}^{3}$ of low-carbon hooked-end steel fibers having a total length of $60 \mathrm{~mm}$, a diameter of $1 \mathrm{~mm}$, and a tensile strength of 1,450 MPa. On the contrary, the Bissen slab was reinforced with $100 \mathrm{~kg} / \mathrm{m}^{3}$ of crimped steel fibers having a length of $50 \mathrm{~mm}$, a diameter of $1.3 \mathrm{~mm}$, and 


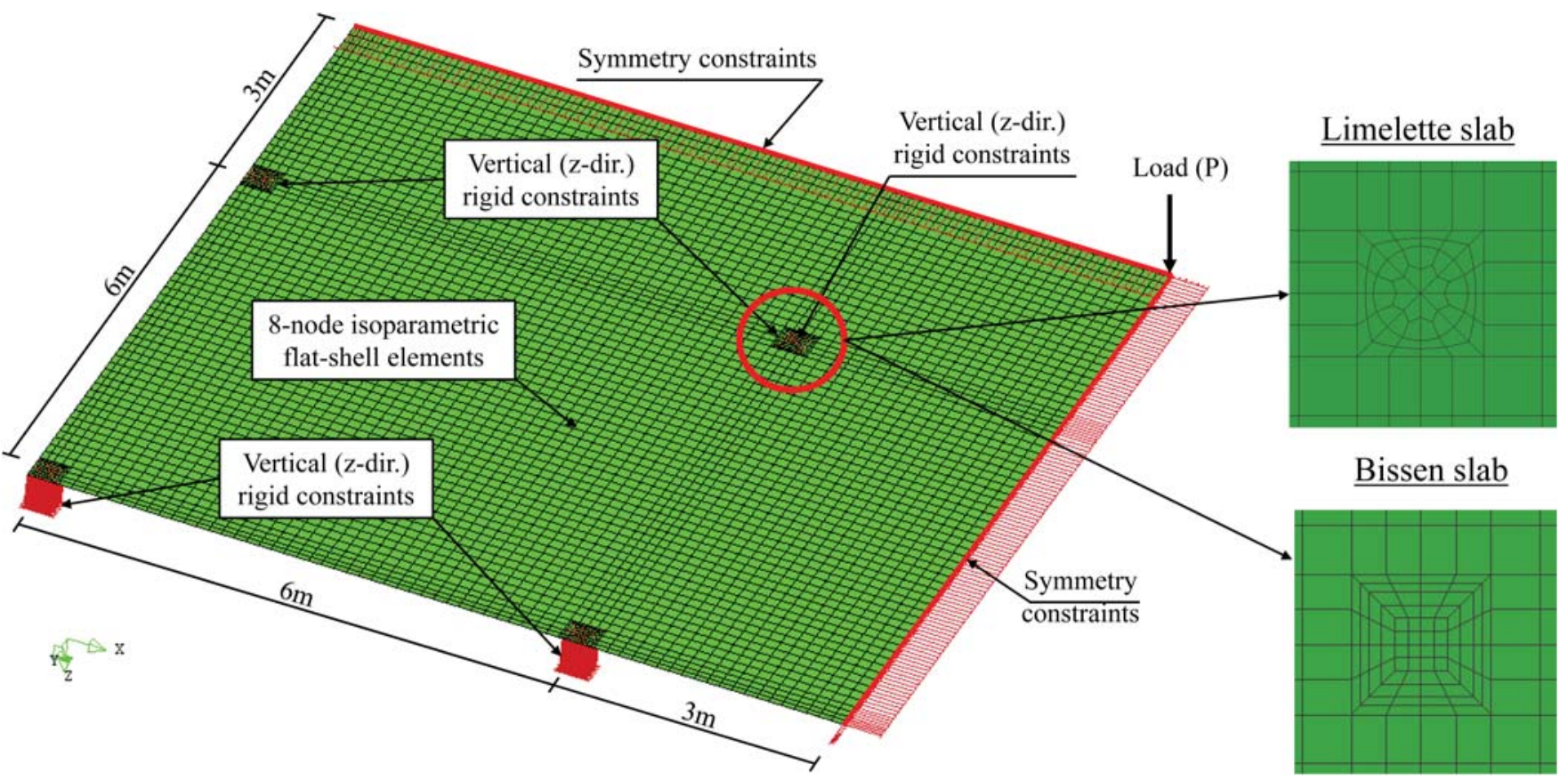

FIGURE 6 Schematic of the finite element mesh of the two elevated slabs

a tensile strength of $900 \mathrm{MPa}$. Table 1 summarizes the parameters that characterize the trilinear stress-crack width relationship herein used for NLFEAs.

The analyses were performed by first applying the selfweight $\left(4.8 \mathrm{kN} / \mathrm{m}^{2}\right)$ and by then monotonically increasing the point load. The arc-length method was adopted to get the indirect control of deflection.

The load $(P)$ - center deflection $(\delta)$ diagram of Figure 7 compares the response of the numerical simulations with those resulting from the full-scale experimental tests.

The numerical response of the Limelette slab resulted to be consistent with the experimental one in terms of initial stiffness and maximum capacity, being the latter equal to $326 \mathrm{kN}$ both in the simulation and the experimental tests. Unlike the numerical simulation, the experimental response was characterized by a slightly higher ultimate deflection. However, the good prediction of the maximum deflection

TABLE 1 Limelette and Bissen slab: material properties

\begin{tabular}{llll} 
Property & Unit & $\begin{array}{l}\text { Limelette } \\
\text { slab }\end{array}$ & $\begin{array}{l}\text { Bissen } \\
\text { slab }\end{array}$ \\
\hline Mean modulus of elasticity $\left(E_{\mathrm{cm}}\right)$ & {$[\mathrm{MPa}]$} & 29,000 & 32,300 \\
\hline Poisson's coefficient $(\nu)$ & {$[-]$} & 0.20 & 0.20 \\
\hline Mean cylindrical compressive strength $\left(f_{\mathrm{cm}}\right)$ & {$[\mathrm{MPa}]$} & 36 & 38 \\
\hline Compressive strain at peak strength $\left(\varepsilon_{\mathrm{c} 1}\right)$ & {$[\%$ o $]$} & 2.0 & 2.1 \\
\hline Ultimate compressive strain $\left(\varepsilon_{\mathrm{cu}}\right)$ & {$[\%$ o $]$} & 3.5 & 3.5 \\
\hline Mean tensile strength $\left(f_{\mathrm{ctm}}\right)$ & {$[\mathrm{MPa}]$} & 2.20 & 2.50 \\
\hline Mean postcracking stress $\left(f_{1}\right)$ & {$[\mathrm{MPa}]$} & 1.20 & 1.75 \\
Crack width $\left(w_{1}\right)$ & {$[\mathrm{mm}]$} & 0.05 & 0.25 \\
\hline Mean postcracking stress $\left(f_{2}\right)$ & {$[\mathrm{MPa}]$} & 1.20 & 1.06 \\
Crack width $\left(w_{2}\right)$ & {$[\mathrm{mm}]$} & 1.50 & 1.25 \\
\hline Ultimate crack width $\left(w_{u}\right)$ & {$[\mathrm{mm}]$} & 6.00 & 2.00 \\
\hline
\end{tabular}

observed in the load range $0-300 \mathrm{kN}$ (ie, first branch of the curve) proves the ability of the model to provide reliable results also at SLS conditions.

The simulation of the Bissen slab resulted to be very accurate especially for deflection values ranging from 0 to $27 \mathrm{~mm}$. For higher deflection values, the simulation provided a stiffer response that achieved a maximum capacity $P_{\max }=542 \mathrm{kN}$, which was $17 \%$ higher than that experimentally observed (462 kN). As previously observed for the Limelette slab, the good prediction of the first branch of the curve (ie, load range $0-400 \mathrm{kN}$ ) proves the effectiveness of the model to well predict the structure response even for service loading conditions.

The comparison between the numerical and the experimental crack patterns at failure is of primarily importance to further assess the effectiveness of the model. By considering the similarities between the two analyzed slabs, only the response of the Bissen slab is reported in the following. Figure 8 compares the experimental crack pattern with the numerical maximum principal tensile postcracking strains detected on both the top and bottom surfaces. Referring to the top surface (Figure 8a,c), the numerical model captured the location of the main cracks observed along the alignments of the four inner columns. Unlike the actual crack pattern, the simulation predicted the formation of minor cracks along all the lines connecting the inner columns with those located along the outer border of the slab. The numerical cracks observed in the middle of the slab were due to stress concentration under the applied load.

About the bottom surface (Figure 8b,d), the real crack pattern appears to be consistent with the numerical one. In fact, as observed experimentally, the model detected the formation of two main orthogonal cracks placed in the middle of the structure (see the hot colors in Figure 8d). 


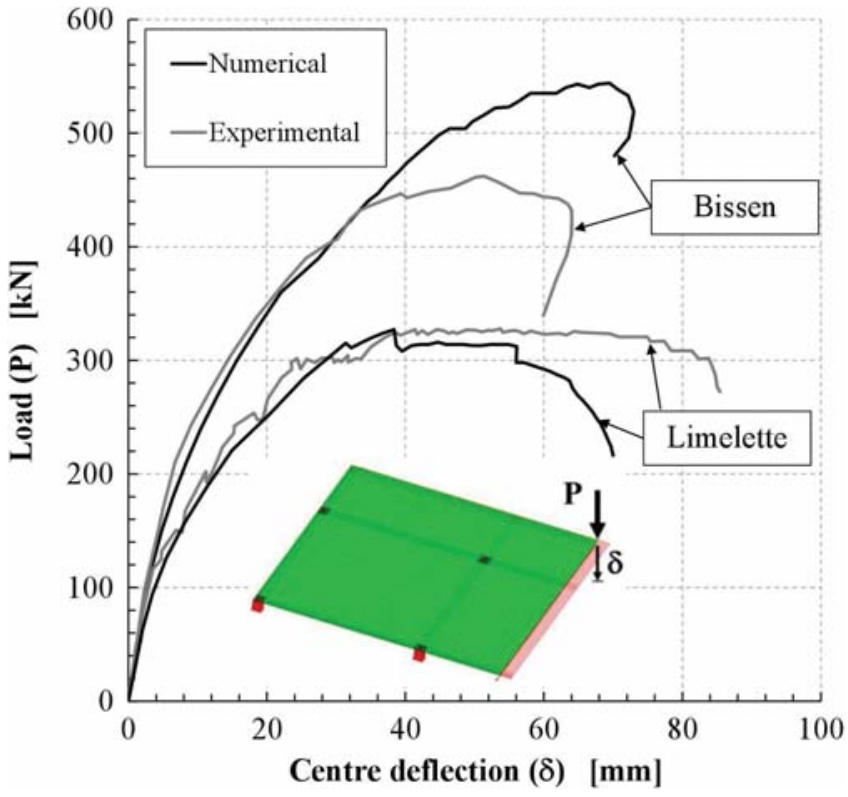

FIGURE 7 Experimental vs numerical load $(P)$ — center deflection $(\delta)$ response of the Bissen and Limelette slab

The previous results prove the ability of the numerical model to provide a reasonable approximation of the actual response of the two case studies considered herein.

\section{I APPLICATION OF THE PROPOSED DESIGN PROCEDURE: A CASE STUDY}

The geometry of the Bissen slab previously analyzed was considered as a reference case study to assess the effectiveness of the proposed design procedure. Therefore, it was assumed that the slab depicted in Figure 1 to be representative of the concrete floor of a typical residential building subjected to uniformly distributed loads (gravity and variable). The results obtained from the implementation of the proposed design procedure are reported and discussed in the following sections. Note that the numerical simulations presented in the following do not take into consideration any creep deformation as well as cracking resulting from the long-term behavior of the slab. Even though the study of long-term conditions is not the main target of this research, it must be always considered in structure design as it may affect the achievement of serviceability requirements for FRC structures (MC2010_clause 7.7.4). The long-term behavior of FRC structures is still one of the open issues not completely included in international codes. Significant information and discussions about this topic can be found in Vasanelli et $\mathrm{al},{ }^{37}$ Mendes et al, ${ }^{38}$ and Pujadas et al. ${ }^{39}$

\section{1 | Slab proportioning}

1. Choice of the geometrical properties. The slab thickness was assumed equal to $200 \mathrm{~mm}$, corresponding to a slenderness ratio of $1 / 35 \leq t / L=1 / 30 \leq 1 / 25(L=6 \mathrm{~m})$.
2. Choice of material mechanical properties. Two different FRC materials, named, respectively, as FRC4c and FRC5e were considered in the study. The two materials present, respectively, a moderate (FRC4c with class 4c) and a very high (FRC5e with class 5e) postcracking performance, according to MC2010 classification (clause 5.6.3). The main mechanical parameters required by the MC2010 to define the compressive and the tensile behavior of FRC are summarized in Table 2. Note that the mean residual stresses $f_{\mathrm{R} 1, \mathrm{~m}}$ and $\mathrm{f}_{\mathrm{R} 3 \text {, }}$ were conventionally assumed as $30 \%$ higher than the corresponding characteristic values (ie, $f_{\mathrm{R} 1, \mathrm{k}}$ and $f_{\mathrm{R} 3, \mathrm{k}}$ ).

The properties of conventional reinforcing steel were consistent with those required by the $\mathrm{MC}^{2010^{1}}$ (clause 5.2) for reinforcing steel B450C (see Table 3). To determine the mean tensile strengths, the corresponding characteristic values were multiplied by 1.1 (see the recommendations for nonlinear analysis reported by EN 1992-2, ${ }^{40}$ clause 5.7).

3. Evaluation of the design actions and linear elastic analysis of the slab. In addition to the slab self-weight $G_{1, \mathrm{k}}$ of $500 \mathrm{kN} / \mathrm{m}^{2}$, a gravity load $G_{2, \mathrm{k}}$ of $4 \mathrm{kN} / \mathrm{m}^{2}$, and a variable load $Q_{k}$ of $2 \mathrm{kN} / \mathrm{m}^{2}$ were here considered. For the sake of structural safety, in order to perform load combinations according to Equation (1), the gravity load $G_{2, \mathrm{k}}$ was considered as a variable load and thus combined with the related partial safety factor suggested by EN 1990 (2006). This is in agreement with the recommendation reported by Eurocode $1^{41}$ at clause 2.1(2). In view of this, the partial safety factor for permanent actions $\left(\gamma_{\mathrm{G} 1}\right)$ was assumed equal to 1 and 1.35 for favorable and unfavorable actions, respectively. About the permanent load $\left(G_{2, \mathrm{k}}\right)$ and the overload $\left(Q_{k}\right)$, the corresponding partial safety factors $\left(\gamma_{\mathrm{G} 2}, \gamma_{Q}\right)$ were both considered equal to 0 for favorable actions and 1.5 for unfavorable actions. The diagram of the design bending moment envelops $\left(m_{\mathrm{Ed}}=m_{\mathrm{Ed}, \mathrm{x}}=m_{\mathrm{Ed}, \mathrm{y}}\right)$ resulting from LEFEA is depicted in Figure 9. The curves represent the maximum moments detected along the most stressed sections (Lines A, B, C, and D) (see also Figures 3 and 4).

4. Design of conventional reinforcement combined with fibers. The additional conventional reinforcement (see Figure 5) was determined, according to the method previously presented, by considering the design bending moments of Figure 9 and the design resisting moment evaluated according to Equation (3). An effective depth (d) of $170 \mathrm{~mm}$ was considered in both directions. The main geometrical properties of the additional reinforcement are summarized in Table 4.

In order to have a better evaluation of the proposed design approach, integrity reinforcement was not considered for the determination of bottom rebars. Structural assessment 
(a)

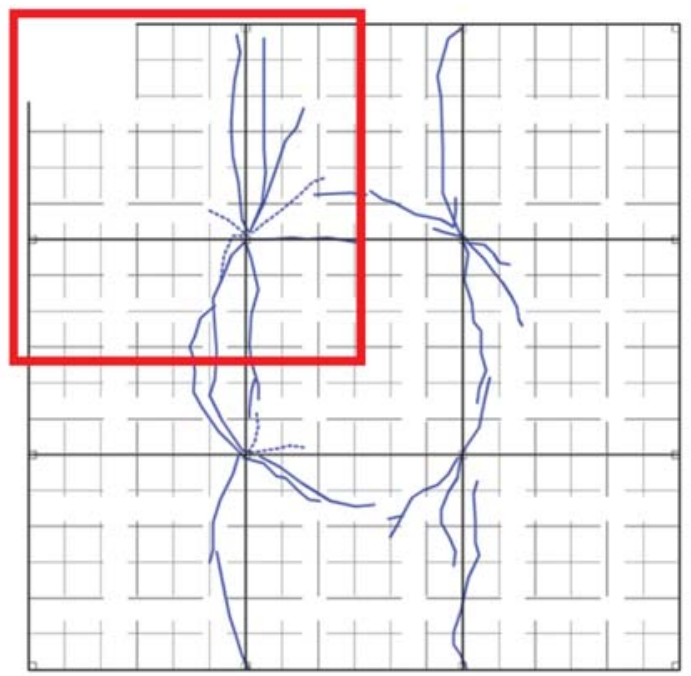

(c)

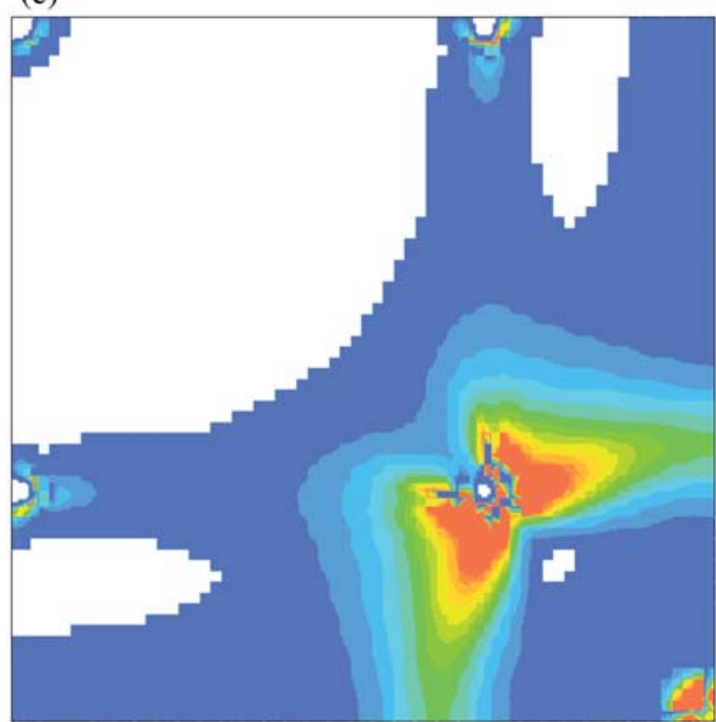

(b)

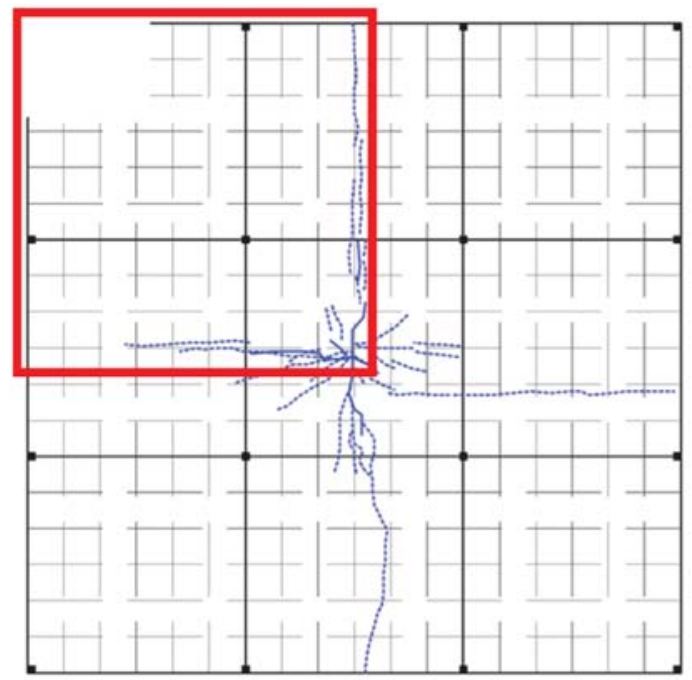

(d)

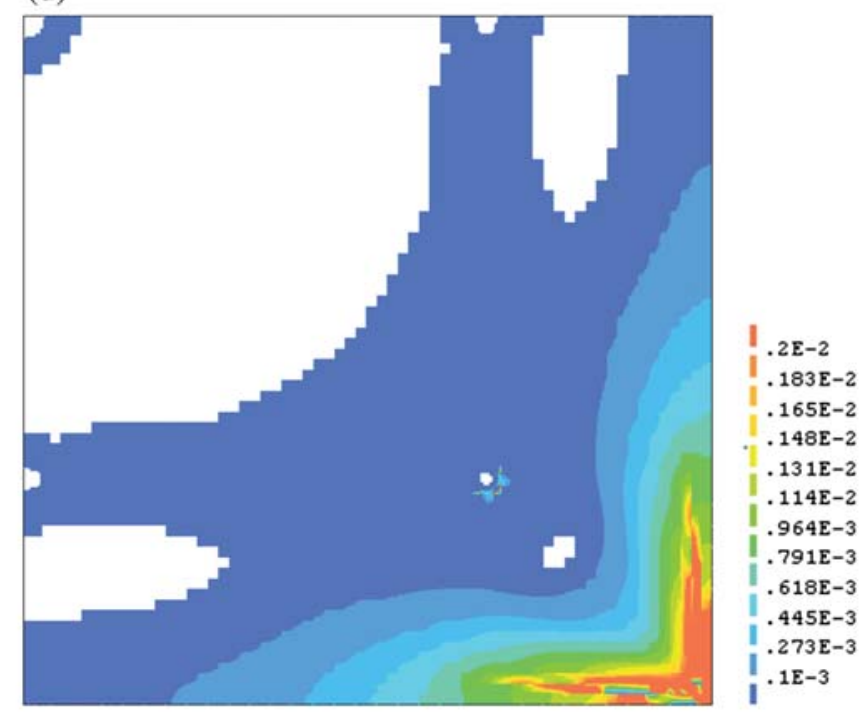

FIGURE 8 Experimental crack pattern observed on the top (a) and bottom (b) surface of the slab. ${ }^{22}$ Numerical contour of principal tensile post-cracking strains: top (c) and bottom (d) view. Note that the numerical contours correspond to the top left quarter of the experiments (see red square) on (a) and (b)

of the design resistance provided by integrity reinforcement after punching will be discussed elsewhere.

\section{2 | Slab verification}

1. Determination of the global resistance $\left(R_{d}\right)$ of the slab by NLFEA. To assess the design resistance of the structure, the method for the ECOV $\left(V_{R}\right)$ proposed by Cervenka $^{42}$ and reported in the MC2010 ${ }^{1}$ (clause 7.11.3.3.2) was adopted. It is therefore assumed that the global safety factor $\gamma^{*}$ is related to $V_{R}$ by the following relationship:

$\gamma_{\mathrm{R}}^{*}=\exp \left(\alpha_{\mathrm{R}} \cdot \beta \cdot \mathrm{V}_{\mathrm{R}}\right)$ with $\mathrm{V}_{\mathrm{R}}=\frac{1}{1.65} \cdot \ln \left(\frac{\mathrm{R}_{\mathrm{m}}}{\mathrm{R}_{\mathrm{k}}}\right)$,

where $\alpha_{R}=0.8 ; \beta=3.8$ (for a service life of 50 years) corresponds to a failure probability of about $10^{-4}$, suitable for buildings (eg, residential and office buildings) generally associated with the medium consequences class (CC2) according to EN $1990^{21}$ Annex B. $R_{m}$ and $R_{k}$ represent the capacity of the structure resulting from the implementation of the mean and characteristic constitutive laws of materials, respectively. The design resistance of the structure $\left(R_{d}\right)$ is determined according to Equation (6) by also including the model uncertainty factor $\gamma_{\mathrm{Rd}}=1.06$. Note that the adopted value of the target reliability index $\beta$ is consistent with that suggested by MC2010 (clause 3.3.3) for ULS verification in case of medium consequence of failure.

Equation (8) was used to describe the compressive behavior of FRC. About the tensile behavior, the bilinear stress-strain model proposed by the MC2010 (clause 5.6.5 - Figure 5.6-11) was adopted. The latter requires the evaluation of two uniaxial tensile strength parameters, that is, $f_{\mathrm{Fts}}=0.45 \cdot f_{\mathrm{R} 1}$ and $f_{\mathrm{ftu}}=0.5 \cdot f_{\mathrm{R} 3}-0.2 \cdot f_{\mathrm{R} 1}$ (see Table 2), corresponding, respectively, to the uniaxial tensile strains $\varepsilon_{\mathrm{SLS}}=\mathrm{CMOD}_{1} / L_{\mathrm{ch}}=0.5 \mathrm{~mm} / L_{\mathrm{ch}}$ and $\varepsilon_{\mathrm{ULS}}=w_{u} / L_{\mathrm{ch}}=2.5 \mathrm{~mm} / L_{\mathrm{ch}}$. 
TABLE 2 Properties of FRC materials used in the design of the floor slab

\begin{tabular}{|c|c|c|c|}
\hline Property & Unit & FRC m & laterial \\
\hline Designation & & $\mathrm{FRC} 4 \mathrm{c}$ & FRC5e \\
\hline Classification (according MC2010) & {$[-]$} & $4 c$ & $5 \mathrm{e}$ \\
\hline Mean modulus of elasticity $\left(E_{\mathrm{cm}}\right)$ & {$[\mathrm{MPa}]$} & 32,800 & \\
\hline Poisson's coefficient $(\nu)$ & {$[-]$} & 0.15 & \\
\hline Mean cylindrical compressive strength $\left(f_{\mathrm{cm}}\right)$ & {$[\mathrm{MPa}]$} & 38 & \\
\hline Characteristic cylindrical compressive strength $\left(f_{\mathrm{ck}}\right)$ & {$[\mathrm{MPa}]$} & 30 & \\
\hline Compressive strain at peak strength $\left(\varepsilon_{\mathrm{c} 1}\right)$ & {$[\% \circ]$} & 2.2 & \\
\hline Ultimate compressive strain $\left(\varepsilon_{\mathrm{cu}}\right)$ & {$[\% o]$} & 3.5 & \\
\hline Mean tensile strength $\left(f_{\mathrm{ctm}}\right)$ & {$[\mathrm{MPa}]$} & 2.9 & \\
\hline Characteristic tensile strength $\left(f_{\mathrm{ctk}}\right)$ & {$[\mathrm{MPa}]$} & 2.0 & \\
\hline Mean residual strength at $\mathrm{CMOD}_{1}=0.5 \mathrm{~mm}\left(f_{\mathrm{R} 1 \mathrm{~m}}\right)$ & {$[\mathrm{MPa}]$} & 5.2 & 6.5 \\
\hline Mean residual strength at $\mathrm{CMOD}_{3}=2.5 \mathrm{~mm}\left(f_{\mathrm{R} 3 \mathrm{~m}}\right)$ & {$[\mathrm{MPa}]$} & 4.7 & 8.5 \\
\hline $\begin{array}{l}\text { Characteristic residual strength at } \\
\qquad \mathrm{CMOD}_{1}=0.5 \mathrm{~mm}\left(f_{\mathrm{R} 1 \mathrm{k}}\right)\end{array}$ & {$[\mathrm{MPa}]$} & 4.0 & 5.0 \\
\hline $\begin{array}{l}\text { Characteristic residual strength at } \\
\qquad \mathrm{CMOD}_{3}=2.5 \mathrm{~mm}\left(f_{\mathrm{R} 3 \mathrm{k}}\right)\end{array}$ & {$[\mathrm{MPa}]$} & 3.6 & 6.5 \\
\hline Mean serviceability residual tensile strength $\left(f_{\mathrm{Fts}, \mathrm{m}}\right)$ & {$[\mathrm{MPa}]$} & 2.3 & 2.9 \\
\hline Mean ultimate residual tensile strength $\left(f_{\mathrm{Ftu}, \mathrm{m}}\right)$ & {$[\mathrm{MPa}]$} & 1.3 & 3.0 \\
\hline $\begin{array}{l}\text { Characteristic serviceability residual tensile strength } \\
\left(f_{\mathrm{Fts}, \mathrm{k}}\right)\end{array}$ & {$[\mathrm{MPa}]$} & 1.8 & 2.3 \\
\hline $\begin{array}{l}\text { Characteristic ultimate residual tensile strength } \\
\qquad\left(f_{\mathrm{Ftu}, \mathrm{k}}\right)\end{array}$ & {$[\mathrm{MPa}]$} & 1.0 & 2.3 \\
\hline
\end{tabular}

As mentioned above, the numerical analyses were carried out by first applying the self-weight and by subsequently increasing the overload up to failure. For the sake of brevity, only the results obtained from the most critical load combination (ie, the one considering the self-weight $\gamma_{\mathrm{G} 1} \cdot G_{1, \mathrm{k}}=1.35 \cdot G_{1, \mathrm{k}}$ and the overload $\gamma_{Q} \cdot\left[G_{2}+Q_{k}\right]=\gamma_{Q} \cdot 6 \mathrm{kN} / \mathrm{m}^{2}$ applied all over the surface of the slab) are reported and discussed. Considering that the self-weight was kept constant, the results reported in the following only refer to the permanent and variable load, whose design value is given by $E_{d}^{\prime}=1.5$. $\left(G_{2 \mathrm{k}}+Q_{k}\right)=9 \mathrm{kN} / \mathrm{m}^{2}$.

The diagram of Figure 10 shows the total overload $E^{\prime}=G_{2 \mathrm{k}}+Q_{k}$ against the maximum deflection detected in the middle of the corner bay of the slab. In addition to the HRC slabs, the slabs reinforced only with fibers were also simulated. The results of the analyses performed with both

TABLE 3 Properties of conventional reinforcing steel

\begin{tabular}{lll} 
Property & Unit & \\
\hline Designation (according EN 1992-1-1) & & B450C \\
Modulus of elasticity $\left(E_{s}\right)$ & {$[\mathrm{MPa}]$} & 210,000 \\
Mean yielding strength $\left(f_{\mathrm{ym}}\right)$ & {$[\mathrm{MPa}]$} & 495 \\
Characteristic yielding strength $\left(f_{\mathrm{yk}}\right)$ & {$[\mathrm{MPa}]$} & 450 \\
Mean ultimate strength $\left(f_{\mathrm{um}}\right)$ & {$[\mathrm{MPa}]$} & 570 \\
Characteristic ultimate strength $\left(f_{\mathrm{uk}}\right)$ & {$[\mathrm{MPa}]$} & 520 \\
Mean ultimate strain $\left(\varepsilon_{\mathrm{um}}\right)$ & {$[\%]$} & 13.0 \\
Characteristic ultimate strain $\left(\varepsilon_{\mathrm{uk}}\right)$ & {$[\%]$} & 8.0 \\
\hline
\end{tabular}

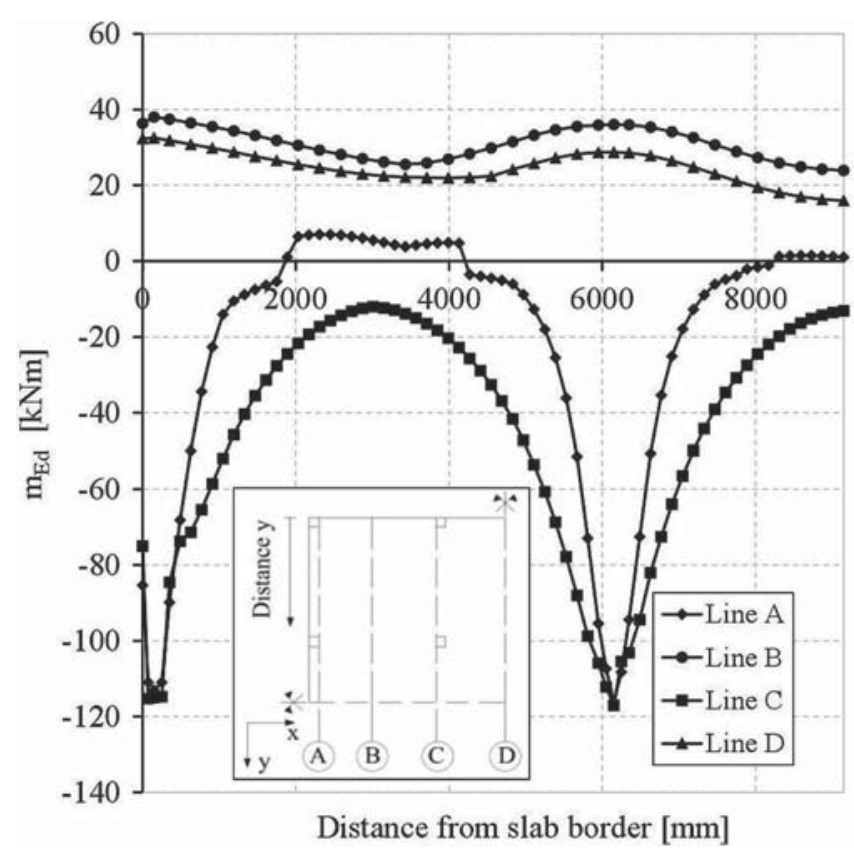

FIGURE 9 Design bending moment envelopes resulting from linear elastic finite element analysis

the mean and the characteristic properties of materials are reported.

The curves show that, irrespective of the FRC performance adopted, the hybrid reinforcement allowed the slabs to achieve similar maximum capacities, able to fulfill the minimum safety requirement, that is, $R_{d} / E_{d}^{\prime} \geq 1$ (see Table 5). As expected, the slabs reinforced only with fibers reached maximum capacities and ductilities significantly lower than those exhibited by the HRC slabs. This result emphasizes the ability of the adopted local reinforcement to enhance the structural performance.

The importance of using top rebars to get the optimal hybrid reinforcement is highlighted by the total overloaddeflection responses shown in Figure 11. The diagram compares the mean response of the slab FRC5e, previously designed, with those exhibited by other two slabs named, respectively, as FRC5e-A and FRC5e-B. The former had the same properties of the slab FRC5e except for the top reinforcement, which was totally removed from the top of the columns. The latter was made with the same conventional reinforcement of the slab FRC5e-A (ie, no top reinforcement) but the tensile behavior of FRC was significantly improved by incrementing the residual strength $f_{\mathrm{R} 3 \mathrm{k}}$ from $6.5 \mathrm{MPa}$ (fiber content of about $48 \mathrm{~kg}$ / $\mathrm{m}^{3}$ ) to $14.3 \mathrm{MPa}$ (fiber content of about $105 \mathrm{~kg} / \mathrm{m}^{3}$ ) for reaching the same capacity of the slab FRC5e.

The analysis results show that the total removal of top reinforcement caused a $22 \%$ reduction of the maximum overload, which changed from $19.0 \mathrm{kN} / \mathrm{m}^{2}$ (slab FRC5e) to $14.9 \mathrm{kN} / \mathrm{m}^{2}$ (slab FRC5e-A). To obtain approximately the same maximum capacity of the slab FRC5e by keeping only the bottom rebars, the use of an 
TABLE 4 Properties of flexural rebars according to the bar layout of Figure 5

\begin{tabular}{|c|c|c|c|c|c|c|c|c|}
\hline \multirow[b]{2}{*}{$\begin{array}{l}\text { Reinforcement } \\
\text { type }\end{array}$} & \multicolumn{4}{|c|}{ Material: FRC4c } & \multicolumn{4}{|c|}{ Material: FRC5e } \\
\hline & $\begin{array}{l}\text { Bar } \\
\text { type }\end{array}$ & $\begin{array}{l}\text { Total } \\
\text { bar area }\end{array}$ & $\begin{array}{l}\text { Bar } \\
\text { length }\left(L_{\mathrm{s} 1}\right)\end{array}$ & $\begin{array}{l}\text { Bar } \\
\text { length }\left(L_{\mathrm{s} 2}\right)\end{array}$ & $\begin{array}{l}\text { Bar } \\
\text { type }\end{array}$ & $\begin{array}{l}\text { Total } \\
\text { bar area }\end{array}$ & $\begin{array}{l}\text { Bar } \\
\text { length }\left(L_{\mathrm{s} 1}\right)\end{array}$ & $\begin{array}{l}\text { Bar } \\
\text { length }\left(L_{\mathrm{s} 2}\right)\end{array}$ \\
\hline$[-]$ & {$[-]$} & {$\left[\mathrm{mm}^{2}\right]$} & {$[\mathrm{mm}]$} & {$[\mathrm{mm}]$} & {$[-]$} & {$\left[\mathrm{mm}^{2}\right]$} & {$[\mathrm{mm}]$} & {$[\mathrm{mm}]$} \\
\hline$A_{s, x 1}^{t}=A_{s, y 1}^{t}$ & $5 \Phi 16$ & 1,005 & 800 & - & $4 \Phi 16$ & 804 & 700 & - \\
\hline $\mathrm{A}_{\mathrm{s}, \mathrm{x} 2}^{\mathrm{t}}=\mathrm{A}_{\mathrm{s}, \mathrm{y} 3}^{\mathrm{t}}$ & $7 \Phi 16$ & 1,407 & & 800 & $5 \Phi 16$ & 1,005 & & 700 \\
\hline $\mathrm{A}_{\mathrm{s}, \mathrm{x} 3}^{\mathrm{t}}=\mathrm{A}_{\mathrm{s}, \mathrm{y} 2}^{\mathrm{t}}$ & $5 \Phi 20$ & 1,571 & 1,000 & 1,000 & $6 \Phi 16$ & 1,206 & 800 & 800 \\
\hline $\mathrm{A}_{\mathrm{s}, \mathrm{x} 4 \cdot}^{\mathrm{t}}=\mathrm{A}_{\mathrm{s}, \mathrm{y} 4}^{\mathrm{t}}$ & $10 \Phi 20$ & 3,142 & & & $8 \Phi 20$ & 2,513 & & \\
\hline$A_{s, x 1}^{b}=A_{s, y 1}^{b}$ & $6 Ф 14$ & 924 & - & - & $3 \Phi 12$ & 339 & - & - \\
\hline$A_{s, x 2}^{b}=A_{s, y 2}^{b}$ & $8 \Phi 16$ & 1,608 & - & - & $3 \Phi 14$ & 462 & - & - \\
\hline$A_{s, x 3}^{b}=A_{s, y 3}^{b}$ & $4 \Phi 14$ & 615 & - & - & $2 \Phi 8$ & 101 & - & - \\
\hline$A_{s, x 4}^{b}=A_{s, y 4}^{b}$ & $5 \Phi 14$ & 770 & - & - & - & - & - & - \\
\hline
\end{tabular}

Abbreviation: FRC, fiber-reinforced concrete.

FRC having a significantly higher (ie, $+120 \%$ ) value of $f_{\mathrm{R} 3 \mathrm{k}}$ was required (see slab FRC5e-B). The disadvantage resulting from the lack of top reinforcement is well highlighted by the comparison of the total steel contents (not including rebar detailing) of the slabs FRC5e and FRC5e-B, which were approximately equal to 55 and $107 \mathrm{~kg} / \mathrm{m}^{3}$, respectively. The high gap between these steel contents proves the effectiveness of top reinforcement in providing the required structure capacity by limiting, at the same time, the total amount of reinforcement.

2. Ductility requirements according MC2010. As required by MC2010 (see clause 7.7.2), FRC structures must satisfy at least one of the two ductility conditions:

$$
\begin{gathered}
\delta_{\mathrm{u}} \geq 20 \cdot \delta_{\mathrm{SLS}}, \\
\delta_{\text {peak }} \geq 5 \cdot \delta_{\mathrm{SLS}},
\end{gathered}
$$

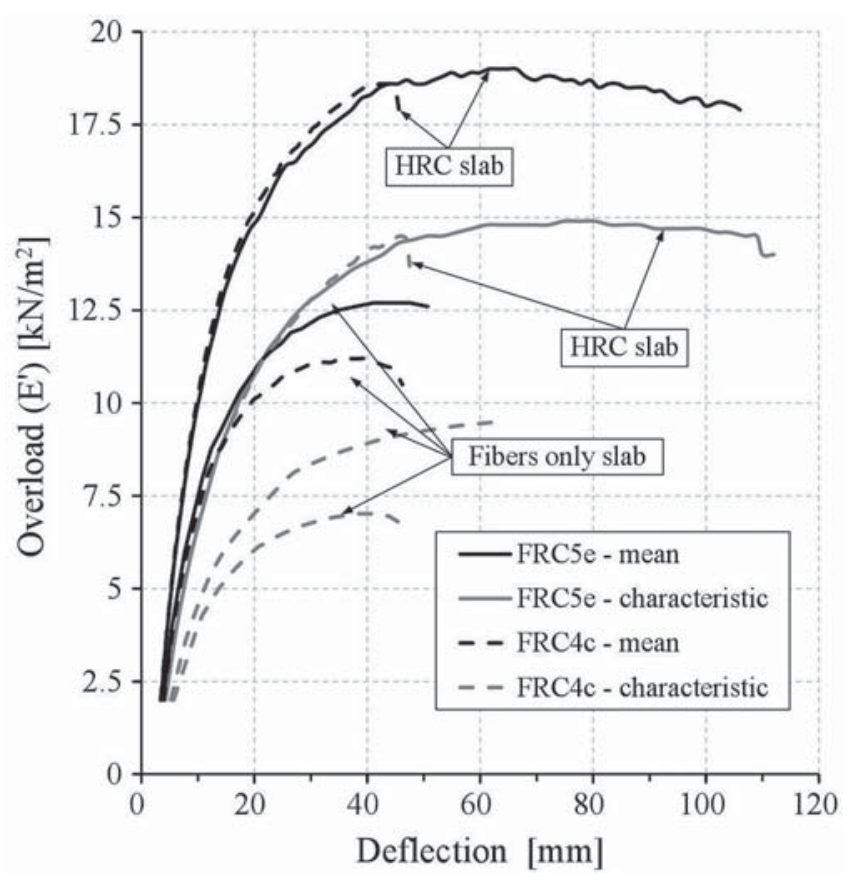

FIGURE 10 Total overload-deflection response of the slabs where $\delta_{u}$ is the displacement corresponding to the ultimate capacity $\left(P_{u}\right), \delta_{\text {peak }}$ is the displacement at the maximum load $\left(P_{\max }\right)$, and $\delta_{\mathrm{SLS}}$ is the deflection at the service load determined by performing a linear elastic analysis. In addition to Equations (10) and (11), the ultimate load $P_{u}$ has to be higher than both the first cracking load $\left(P_{\mathrm{cr}}\right)$ and the maximum service load $P_{\mathrm{SLS}}$. The previous load and deflection values are all derived from NLFEAs performed with mean properties of materials.

While the previous equations are mandatory for members containing fibers only, in the case of HRC elements one may argue whether the classical approach for FRC only would suffice as check. In spite of this, Equations (10) and (11) are considered and critically discussed for the HRC slabs studied herein.

Here, the service load deflection $\left(\delta_{\mathrm{SLS}}\right)$ was determined for a service load $\left(E_{\mathrm{SLS}}^{\prime}\right)$ equal to $6.0 \mathrm{kN} / \mathrm{m}^{2}$, whereas the deflection $\delta_{\text {peak }}$ corresponds to the mean slab capacity $R_{m}$. Moreover, the ultimate deflection $\left(\delta_{u}\right)$ was assumed as the maximum deflection at which the numerical simulation was interrupted because of slab collapse. According to the results of the analyses, all the slabs exhibited first cracking right after the application of self-weight.

The results reported in Table 5 prove that all the slabs fulfilled Equation (11) while they failed the verification requirement related to the ultimate deflection represented by Equation (10).

Other analytical models, available in literature, ${ }^{43}$ could also be utilized for verifying ULS and SLS compliance. However, as Equation (11) was satisfied, the proposed reinforcement fulfills the ductility requirements of MC2010.

3. Verification of punching resistance. Punching shear can significantly affect the ultimate resistance of flat slabs. The effects of punching on FRC structures have been investigated by different authors. ${ }^{28,44,45}$ About code provisions, MC2010 (clause 7.7.3.5.3) reports a detailed procedure for the verification of FRC members that is 
TABLE 5 Results of slab verification

\begin{tabular}{|c|c|c|c|c|c|c|c|c|c|c|c|c|c|}
\hline Material & & $\mathbf{R}_{\mathbf{m}}$ & $\mathbf{R}_{\mathbf{k}}$ & $\gamma_{\mathrm{R}}^{*}$ & $\mathbf{R}_{\mathbf{d}}$ & $E_{\text {d }}^{\prime}$ & $\begin{array}{l}R_{d} / E_{d}^{\prime} \\
\text { (check) }\end{array}$ & $E_{\text {SLS }}^{\prime}$ & $\delta_{\mathrm{SLS}}$ & $\delta_{\text {peak }}$ & $\delta_{u}$ & $\begin{array}{l}\delta_{u} / \delta_{\mathrm{SLS}} \\
\text { (check) }\end{array}$ & $\begin{array}{l}\delta_{\text {peak }} / \\
\delta_{\text {SLS }} \\
(\text { check) }\end{array}$ \\
\hline & & {$\left[\mathrm{kN} / \mathrm{m}^{2}\right]$} & {$\left[\mathrm{kN} / \mathrm{m}^{2}\right]$} & {$[-]$} & {$\left[\mathrm{kN} / \mathrm{m}^{2}\right]$} & {$\left[\mathrm{kN} / \mathrm{m}^{2}\right]$} & {$[-]$} & {$\left[\mathrm{kN} / \mathrm{m}^{2}\right]$} & [mm] & {$[\mathrm{mm}]$} & {$[\mathrm{mm}]$} & & \\
\hline \multirow[t]{2}{*}{$\mathrm{FRC4c}$} & HRC & 18.6 & 14.5 & 1.68 & 11.1 & 9.0 & $1.2(\mathrm{OK})$ & 6.0 & 8.0 & 42.0 & 46.0 & 5.8 (NO) & $5.3(\mathrm{OK})$ \\
\hline & Fibers only & 11.2 & 7.0 & 2.4 & 4.5 & & 0.5 (NO) & & 8.3 & 41.5 & 46.2 & $5.6(\mathrm{NO})$ & $5.0(\mathrm{OK})$ \\
\hline \multirow[t]{2}{*}{ FRC5e } & $\mathrm{HRC}$ & 19.0 & 14.9 & 1.65 & 11.5 & & $1.3(\mathrm{OK})$ & & 8.0 & 64.8 & 106 & 13 (NO) & $8.1(\mathrm{OK})$ \\
\hline & Fibers only & 12.7 & 9.5 & 1.7 & 7.0 & & 0.8 (NO) & & 8.2 & 47.6 & 51 & $6.2(\mathrm{NO})$ & $5.8(\mathrm{OK})$ \\
\hline
\end{tabular}

Abbreviations: FRC, fiber-reinforced concrete; HRC, hybrid reinforced concrete; SLS, serviceability limit state.

here recommended for designing and check the ultimate behavior of elevated slabs. The verification of punching mechanisms was not the main target of the present work and, thus, it will be presented and discussed elsewhere.

\section{5 | OPTIMIZED HYBRID}

\section{REINFORCEMENT FOR ELEVATED SLABS}

The approach proposed for the reinforcement of the slab (see Section 2.1) allows designing the required amount of conventional reinforcement once FRC residual strength is selected. It is worth remarking that the choice of the FRC postcracking strength is not of minor importance as it affects the total amount of rebars.

As an example, the hybrid reinforcement of the $200 \mathrm{~mm}$ thick elevated slab analyzed in Section 3 was designed to withstand two different variable loads $\left(Q_{k}\right)$, respectively equal to 2 and $4 \mathrm{kN} / \mathrm{m}^{2}$, in addition to the gravity loads $G_{1, \mathrm{k}}+G_{2, \mathrm{k}}=500+400=900 \mathrm{kN} / \mathrm{m}^{2}$. Eight different FRC materials having different performance levels $\left(f_{\mathrm{R} 3 \mathrm{k}}\right.$ from 2 to

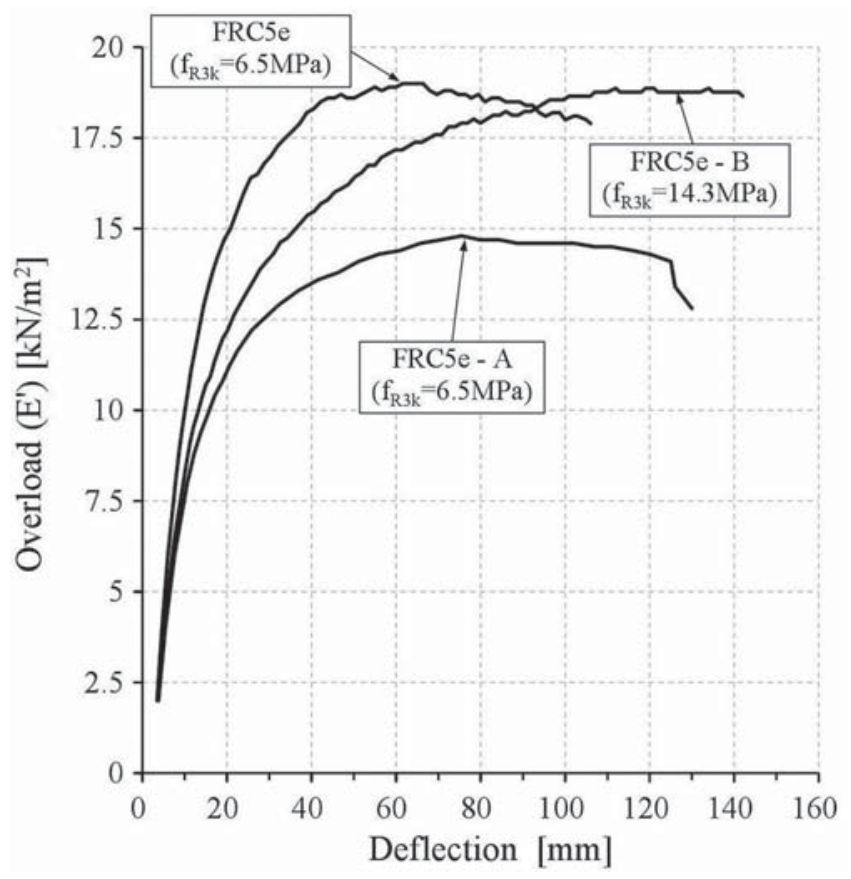

FIGURE 11 Total overload-deflection mean response of different hybrid reinforced concrete slabs: effect of top reinforcement removal
$10 \mathrm{MPa}$, corresponding to steel-fiber contents ranging from 15 to $70 \mathrm{~kg} / \mathrm{m}^{3}$ ) were taken from the database of the University of Brescia (including 528 samples) and adopted for this example. As discussed in Tiberti et $\mathrm{al}^{46}$ the database includes FRC materials characterized by fiber volume fractions ranging from $0.32 \%$ to $1 \%$, fiber aspect ratios ranging from 44 to 100 and fiber tensile strengths ranging from 1,100 to 3,100 MPa. From a regression analysis (see Tiberti et $\mathrm{al}^{44}$ ), the following equation was proposed to determine the mean residual strength $f_{\mathrm{R} 3 \mathrm{~m}}$ :

$$
\frac{\mathrm{f}_{\mathrm{R} 3 \mathrm{~m}}}{\sqrt{\mathrm{f}_{\mathrm{cm}, \text { cube }}}}=1.430 \cdot\left[\mathrm{V}_{\mathrm{f}} \cdot\left(\mathrm{L}_{\mathrm{f}} / \emptyset_{\mathrm{f}}\right) \cdot \mathrm{f}_{\mathrm{uf}}\right], .
$$

where $f_{\text {cm,cube }}(\mathrm{MPa})$ is the mean compressive cubic strength of concrete; $V_{f}$ is the volume fraction of fibers; $L_{f} / \Phi_{f}$ is the fiber aspect ratio; and $f_{\text {uf }}(\mathrm{GPa})$ is the fiber tensile strength.

In the present example, the FRCs considered had a cylindrical mean compressive strength of $38 \mathrm{MPa}$ (ie, mean cubic strength of about $46 \mathrm{MPa}$ ) and were made with steel fibers having a tensile strength of $2 \mathrm{GPa}$ and an aspect ratio of 80 . As suggested in MC2010, the characteristic value of the tensile strength $f_{\mathrm{R} 3 \mathrm{k}}$ was assumed equal to $0.7 f_{\mathrm{R} 3 \mathrm{~m}}$.

Based on the reinforcement determined according to Section 2, the diagram of Figure 12 reports the total steel content (fiber dosage $+P_{\text {rebars }} / V_{\text {concrete }}\left[\mathrm{kg} / \mathrm{m}^{3}\right]$, where $P_{\text {rebars }}$ is the total weight of conventional reinforcement and $V_{\text {concrete }}$ is the total slab volume) as a function of the characteristic residual strength $f_{\mathrm{R} 3 \mathrm{k}}$ of FRC. The total steel content was estimated either by neglecting reinforcement detailing (continuum line) or by assuming an additional percentage of $20 \%$ of reinforcement weight in order to consider anchorages and splices (dashed line).

The curves highlight that there is a value of the fiber dosage able to minimize the total steel content (fibers + rebars), leading to the optimized combination of fibers and rebars. As expected, the lower is the load the lower is the optimized value of the residual strength $f_{\mathrm{R} 3 \mathrm{k}}\left(\mathrm{ie}\right.$, optimized $f_{\mathrm{R} 3 \mathrm{k}}=4.8 \mathrm{MPa}$ for $G_{2, \mathrm{k}}+Q_{k}=6.0 \mathrm{kN} / \mathrm{m}^{2}$ and $f_{\mathrm{R} 3 \mathrm{k}}=5.5 \mathrm{MPa}$ for $G_{2, \mathrm{k}}+Q_{k}=8.0 \mathrm{kN} / \mathrm{m}^{2}$ ). However, when adopting $f_{\mathrm{R} 3 \mathrm{k}}$ values slightly smaller than the optimized one, the total amount of reinforcement does not change significantly. On the contrary, it is not convenient to use an FRC with a residual strength $f_{\mathrm{R} 3 \mathrm{k}}$ too high than the optimized one as the total amount of reinforcement remarkably increases. In summary, it seems 


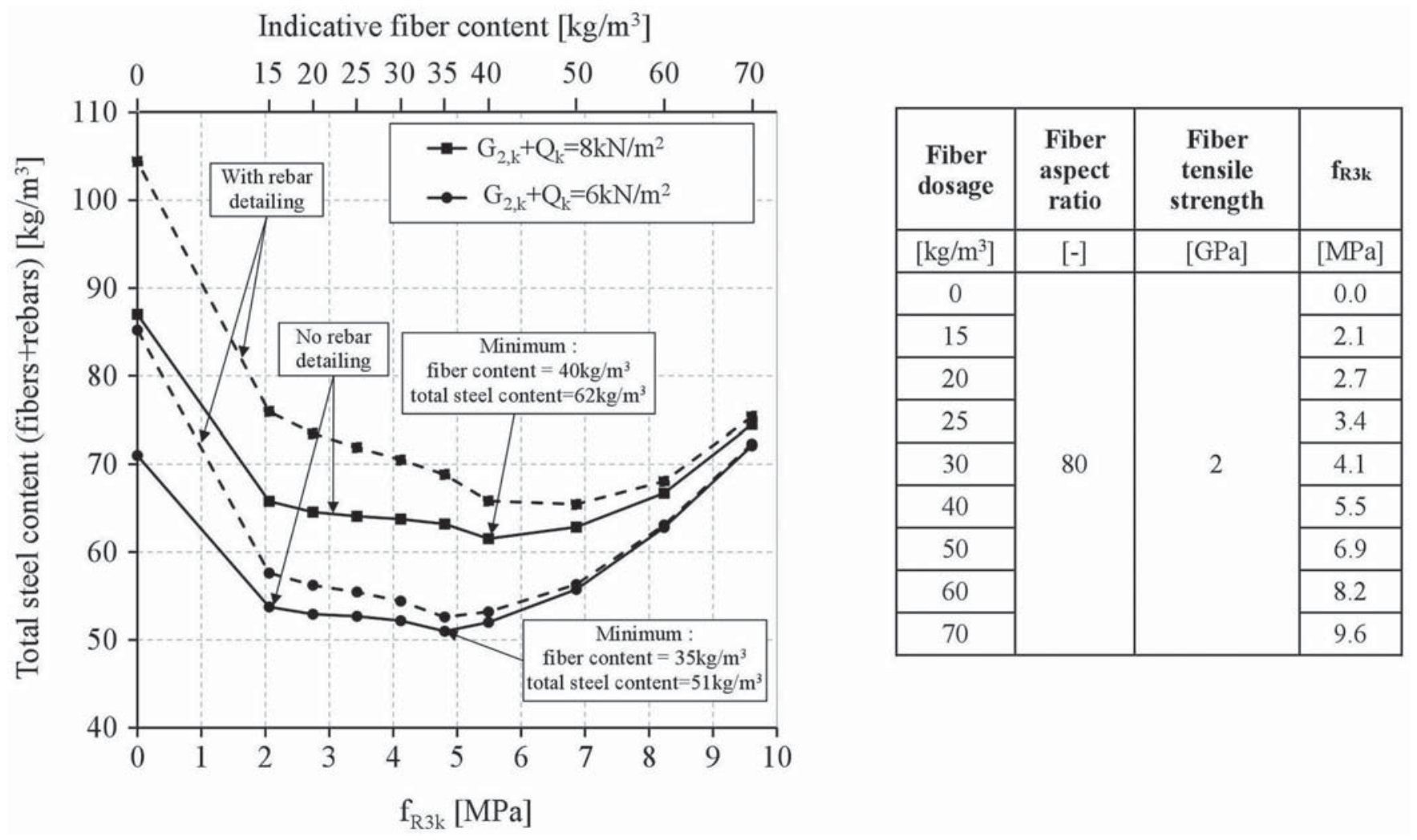

FIGURE 12 Total steel content vs $f_{\mathrm{R} 3 \mathrm{k}}$ response, resulting from a parametric study on a 200-mm-thick slab containing the hybrid reinforcement designed according to the proposed design method

that an FRC having $f_{\mathrm{R} 3 \mathrm{k}}$ ranging between 4 and $5 \mathrm{MPa}$ provides the optimized reinforcement for the adopted design loads $\left(\mathrm{G}_{2, \mathrm{k}}+\mathrm{Q}_{\mathrm{k}}=6.0-8.0 \mathrm{kN} / \mathrm{m}^{2}\right)$, which are commonly used in building design. FRC performance should be slightly increased for higher design loads. Since a strain-hardening behavior in bending allows a better stress redistribution, the suggested FRC minimum performance could be $4 \mathrm{c}$ or $5 \mathrm{c}$ according to MC 2010.

As compared to the RC slabs (ie, $f_{\mathrm{R} 3 \mathrm{k}}=0$ ), which are respectively characterized by a total steel content (not including rebar detailing) of $71 \mathrm{~kg} / \mathrm{m}^{3}\left(G_{2, \mathrm{k}}+Q_{k}=6 \mathrm{kN} / \mathrm{m}^{2}\right)$ and $87 \mathrm{~kg} / \mathrm{m}^{3}\left(G_{2, \mathrm{k}}+Q_{k}=8 \mathrm{kN} / \mathrm{m}^{2}\right)$, the total reinforcement amount of the optimized HRC slabs is about $30 \%$ lower. In practice, the advantage from using FRC is even more significant considering the lower labor required for placing conventional reinforcement.

\section{6 | CONCLUDING REMARKS}

One of the most promising structural applications of FRC is represented by elevated slabs due to the high degree of redundancy of these structures. The real applications available usually adopt high amounts of steel fibers as the main flexural reinforcement, whereas conventional rebars are mainly used as structural integrity reinforcement.

In the present work, a procedure for designing FRC elevated slabs, based on an optimized combination of traditional rebars and fiber reinforcement (HRC), is proposed in accordance with the MC2010 provisions.

The results presented and discussed in the manuscript yield the following conclusions:

- The proposed design method provides an easy and straightforward procedure for proportioning the hybrid reinforcement by performing a linear elastic analysis of the structure.

- The reliability of the proposed design procedure was checked by performing NLFEAs of a particular elevated slab reported by literature. Such analyses proved the ability of the proposed hybrid reinforcement to provide the slab with a structural behavior consistent with the safety and serviceability requirements recommended by MC2010. To corroborate the general reliability of the proposed method, future experimental and numerical research will be carried out to investigate other case studies characterized by different geometries and loading conditions.

- Depending on the load applied and the slab geometry, there is an FRC performance (ie, residual strength $f_{\mathrm{R} 3 \mathrm{k}}$ ) that combined with properly placed rebars is able to minimize the total amount of reinforcement leading to a reduction even greater than $30 \%$ compared to conventional RC slabs. This reinforcement reduction becomes even more significant for practice by considering the labor-time savings. 
- The use of top reinforcement on the columns in combination with bottom rebars appears to be fundamental to optimize total reinforcement. In fact, if top reinforcement is not adopted, a remarkable amount of fibers should be used for increasing the FRC strength in order to resist negative moments.

\section{ORCID}

Luca Facconi (D) http://orcid.org/0000-0003-2202-5439

Fausto Minelli (D) http://orcid.org/0000-0002-4554-4285

\section{REFERENCES}

1. fib Model Code for Concrete Structures 2010. Fédération Internationale du Béton. Lausanne: Ernst \& Sohn, 2013.

2. DafStb Guideline Steel fibre reinforced concrete, German Committee for reinforced concrete; 2014.

3. Norme Tecniche per le Costruzioni, NTC. Norme Tecniche per le Costruzioni, Ministerial Decree 17/01/2018, Official Gazette n. 42; 20 February 2018.

4. Sorelli L, Meda A, Plizzari G. Steel fiber concrete slabs on ground: A structural matter. ACI Struct J. 1997;103(4):551-558.

5. Silfwerbrand J. Design of steel fiber-reinforced concrete slabs on grade for restrained loading. In: Di Prisco M, Plizzari GA, Roberto F, eds. Sixth RILEM Symposium on Fiber-Reinforced Concretes (BEFIB 2004), Bagneaux, France: RILEM Publications; 2004; p. 975-984

6. Barragán B, Facconi L, Laurence O, Plizzari G. Design of glass-fibre-reinforced concrete floors according to the fib Model Code 2010. In: Massicotte B, Charron J-P, Plizzari G, Mobasher B, eds. Fibre reinforced concrete: from design to structural applications - FRC 2014: ACI-fib International Workshop. FIB Bulletin 79-ACI SP-310; 2016, p. 311-320.

7. Destrée $X$. Structural application of steel fibers as only reinforcing in free suspended elevated slabs: Conditions-Design examples. In: Di Prisco M, Plizzari GA, Roberto F, eds. Sixth RILEM Symposium on Fiber-Reinforced Concretes (BEFIB 2004). Bagneaux, France: RILEM Publications; 2004. p. 1073-1082.

8. Gossla U. Flachdecken aus Stahlfaserbeton, Beton-und Stahlbetonbau 101. Heft. 2006;2:94-102. (in German).

9. Barros JAO, Salehian H, Pires NMMA, Gonçalves DMF. Design and testing elevated steel fiber reinforced self-compacting concrete slabs. In: Barros J, Sena-Cruz J, Ferreira R, Valente I, Azenha M, Dias S. eds. BEFIB2012-Fiber Reinforced Concrete, RILEM Publications SARL; 2012; 12 pp.

10. Parmentier B, Van Itterbeeck $P$, Skowron A. The behavior of SFRC flat slabs: The Limelette full-scale experiments for supporting design model codes. In: Charron JP, Massicotte B, Mobasher B, Plizzari G, eds. FRC 2014 Joint ACI-fib International Workshop - Fibre-reinforced Concrete: From Design to Structural Applications - FRC 2014: ACI-fib International Workshop. FIB Bulletin 79 - ACI SP-310; 2016

11. Mitchell D, Cook WD. Preventing progressive collapse of slab structures. J Struct Eng. 1984;110(7):1513-1532. https://doi.org/10.1061/(ASCE) 0733-9445(1984)110:7(1513).

12. Sasani M, Sagiroglu S. Progressive collapse of reinforced concrete structures: A multihazard perspective. ACI Struct J. 2008;105(1):96-103.

13. ACI 544.6R-15-Report on design and construction of steel fiber-reinforced concrete elevated slabs. Reported by ACI Committee 544. Farmington Hills, MI: American Concrete Institute; 2015 ISBN 978-1-942727-32-3.

14. di Prisco M, Plizzari G, Vandewalle L. Structural design according to fib MC 2010: Comparison between RC and FRC elements. In: Massicotte B, Charron J-P, Plizzari G, Mobasher B, eds, Fibre reinforced concrete: from design to structural applications - FRC 2014: ACI-fib International Workshop. FIB Bulletin 79 - ACI SP-310; 2016, p. 311-20. p. 69-87

15. Facconi L, Minelli F, Plizzari G, Pasetto A. Precast fibre-reinforced self-compacting concrete slabs. In: Massicotte B, Charron J-P, Plizzari G, Mobasher B, eds, Fibre reinforced concrete: from design to structural applications - FRC 2014: ACI-fib International Workshop. FIB Bulletin 79 - ACI SP-310; 2016, p. 223-38.
16. de la Fuente A, Pujadas $P$, Blanco A, Aguado A. Experiences in Barcelona with the use of fibres in segmental linings. Tunnelling Undergr Space Technol. 2012;27(1):60-71

17. Tiberti G, Minelli F, Plizzari G. Reinforcement optimization of fiber reinforced concrete linings for conventional tunnels. Composites Part B. 2014; 58:199-207. ISSN 1359-8368.

18. Facconi L, Minelli F, Plizzari G. Steel fiber reinforced self-compacting concrete thin slabs - Experimental study and verification against Model Code 2010 provisions. Eng Struct. 2016;122:226-237.

19. Vandewalle L. Cracking behaviour of concrete beams reinforced with a combination of ordinary reinforcement and steel fibers. Mater Struct. 2000; 33(3):164-170.

20. Chiaia B, Fantilli A, Vallini P. Combining fiber-reinforced concrete with traditional reinforcement in tunnel linings. Eng Struct. 2009;31(7):1600-1606.

21. Mobasher B, Yao Y, Soranakom C. Analytical solutions for flexural design of hybrid steel fiber reinforced concrete beams. Eng Struct. 2015;100: 164-177. ISSN 0141-0296.

22. Destrée X, Mandl J. Steel fibre only reinforced concrete in free suspended elevated slabs: Case studies, design assisted by testing route, comparison to the latest SFRC standard documents. In: Walraven J, Stoelhorst D, editors. Tailor made structure, international FIB 2008 symposium. Amsterdam, Boca Raton, FL: CRC Press, 2008; p. 111.

23. EN 1990. Eurocode 0-Basis of structural design. Brussels: European Committee for Standardization, 2006.

24. EN 14651-5. Precast Concrete Products-Test Method for Metallic Fibre Concrete-Measuring the Flexural Tensile Strength. Brussels, Belgium: European Standard, European Committee for Standardization, 2005.

25. Paulay T, Priestley MJN. Seismic design of concrete and masonry structures. New York: John Wiley and Sons, 1992.

26. Fernández RM, Mirzaei Y, Muttoni A. Post-punching behavior of flat slabs. ACI Struct J. 2013;110:801-812.

27. Schlune H, Gylltoft K, Plos M. Safety formats for non-linear analysis of concrete structures. Mag Concr Res. 2012;64:563-574.

28. Allaix DL, Carbone VI, Mancini G. Global safety format for non-linear analysis of reinforced concrete structures. Struct Concr. 2013;14:29-42. https:// doi.org/10.1002/suco.201200017.

29. Belletti B, Pimentel M, Scolari M, Walraven JC. Safety assessment of punching shear failure according to the level of approximation approach. Struct Concr. 2015;16:366-380. https://doi.org/10.1002/suco. 201500015.

30. Maya LF, Fernandez M, Muttoni A, Foster SJ. Punching shear strength of steel fibre reinforced concrete slabs. Eng Strcut. 2012;40:83-94.

31. Belletti B, Damoni C, Hendriks MAN, de Boer A. Analytical and numerical evaluation of the design shear resistance of reinforced concrete slabs. Struct Concr. 2014;15:317-330. https://doi.org/10.1002/suco.201300069.

32. Diana 10.1. User's manual. Delft, The Netherlands: TNO DIANA BV, 2016.

33. Rots, JG. Computational modelling of concrete fracture [Ph. D. thesis]. Delft University of Technology; 1988.

34. Bažant ZP. Mechanics of fracture and progressive cracking in concrete structures. In: Sih GC, Di Tommaso A, editors. Fracture mechanics of concrete. Structural application and numerical circulation. Dordrecht: Martinus Nijhoff, 1985; p. 1-94.

35. di Prisco M, Martinelli $P$, Parmentier B. On the reliability of the design approach for FRC structures according to fib Model Code 2010: The case of elevated slabs. Struct Concr. 2016:17(4):588-602.

36. Soranakom C, Mobasher B, Destrée X. Numerical simulation of FRC round panel tests and full-scale elevated slabs. Farmington Hills: American Concrete Institute, 2007;p. 31-40.

37. Vasanelli E, Micelli F, Aiello MA, Plizzari G. Long term behavior of FRC flexural beams under sustained load. Eng Struct. 2013;56:1858-1867.

38. Mendes PJD, Barros J, Gonçalves DMF, Sena-Cruz JM. Steel fibre reinforced selfcompacting concrete for lightweight and durable pedestrian bridges: creep behaviour. Proceedings of the 8th RILEM Symposium on Fibre Reinforced Concrete: Challenges and Opportunities (BEFIB 2012). Guimarães, Portugal: Barros Ed, 2012.

39. Pujadas P, Blanco A, Cavalaro S, de la Fuente A, Aguado A, editors. The need to consider flexural post-cracking creep behavior of macro-synthetic fiber reinforced concrete. Construct Build Mater. 2017;149:790-800.

40. EN 1992-2 (2005) Eurocode 2. Design of Concrete Structures. Part 2: Concrete bridges: Design and detailing rules. 
41. EN 1991-1-1 (2002) Eurocode 1. Actions on structures - Part 1-1: General actions - Densities, self-weight, imposed loads for buildings.

42. Cervenka V. Global safety format for nonlinear calculation of reinforced concrete. Beton- und Stahlbetonbau. 2008;103, special edition, Ernst \& Sohn:37-42.

43. Facconi L, Minelli F. Verification of structural elements made of FRC only: A critical discussion and proposal of a novel analytical method. Eng Struct. 2017;131:530-541.

44. Muttoni A, Fernandez M. MC2010: The critical shear crack theory as a mechanical model for punching shear design and its application to code provisions. FIB Bulletin 57: Shear and punching shear in RC and FRC elements. Lausanne (Switzerland), 2010; p. 31-60.

45. Cheng MY, Parra-Montesinos GJ. Evaluation of steel fiber reinforcement for punching shear resistance in slab-column connections - Part I: Monotonically increased load. ACI Struct J. 2010;107(1):101-109.

46. Tiberti G, Germano F, Mudadu A, Plizzari GA. An overview of the flexural post-cracking behavior of steel fiber reinforced concrete. Struct Concr. 2017; 1-24. https://doi.org/10.1002/suco.201700068.

\section{AUTHOR'S BIOGRAPHIES}



Luca Facconi, Ph.D., Post-Doctoral Fellow DICATAM - Department of Civil, Environmental, Architectural Engineering and Mathematics, University of Brescia, Italy luca.facconi@unibs.it

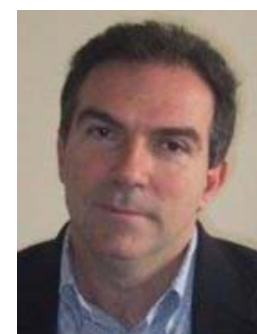

Giovanni Plizzari, Professor of Structural Engineering DICATAM Department of Civil, Environmental, Architectural Engineering and Mathematics, University of Brescia, Italy giovanni.plizzari@unibs.it

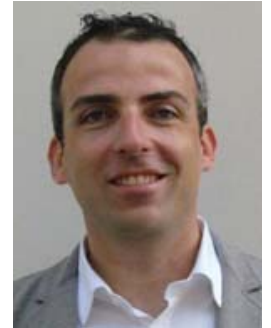

Fausto Minelli, Ph.D., Associate Professor of Structural Engineering DICATAM - Department of Civil, Environmental, Architectural Engineering and Mathematics, University of Brescia, Italy. fausto.minelli@unibs.it

How to cite this article: Facconi L, Plizzari G, Minelli F. Elevated slabs made of hybrid reinforced concrete: Proposal of a new design approach in flexure. Structural Concrete. 2018;1-16. https://doi.org/ $\underline{10.1002 / \text { suco. } 201700278}$ 